\title{
Blinding and Expectancy Confounds in Psychedelic Randomised Controlled Trials
}

\author{
Suresh Muthukumaraswamy ${ }^{1 *}$, Anna Forsyth ${ }^{1}$, Thomas Lumley ${ }^{2}$ \\ ${ }^{1}$ School of Pharmacy, The University of Auckland, Auckland, New Zealand \\ ${ }^{2}$ Department of Statistics, The University of Auckland, Auckland, New Zealand
}

*Corresponding Author:

Suresh Muthukumaraswamy,

School of Pharmacy, University of Auckland.

Private Bag 92019, Auckland 1142, New Zealand.

sd.muthu@auckland.ac.nz 


\section{Abstract}

There is increasing interest in the potential for psychedelic drugs such as psilocybin, LSD and ketamine to treat a number of mental health disorders. To gain evidence for the therapeutic effectiveness of psychedelics, a number of randomised controlled trials (RCTs) have been conducted using the traditional RCT framework and these trials have generally shown promising results, with large effect sizes reported. However, in this paper we argue that estimation of treatment effect sizes in psychedelic clinical trials are likely over-estimated due to de-blinding of participants and high levels of response expectancy generated by RCT trial contingencies. The degree of over-estimation is at present difficult to estimate. We conduct systematic reviews of psychedelic RCTs and show that currently reported RCTs have failed to measure and report expectancy and malicious de-blinding. In order to overcome these confounds we argue that RCTs should routinely measure de-blinding and expectancy and that careful attention should be paid to the clinical trial design used and the instructions given to participants to allow these confounds to be estimated and removed from effect size estimates. We urge caution in interpreting effect size estimates from extant psychedelic RCTs. 


\section{Contents}

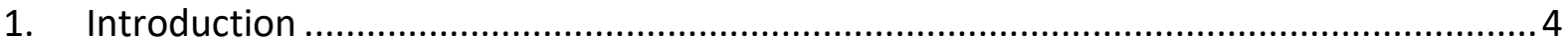

2. Causal Inference and the Randomised Controlled Trial ..............................................4

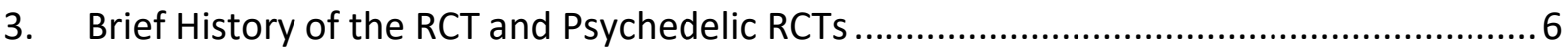

4. Placebo Responses, Expectancy and Alliance........................................................... 7

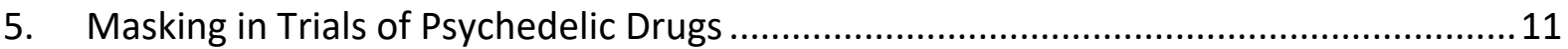

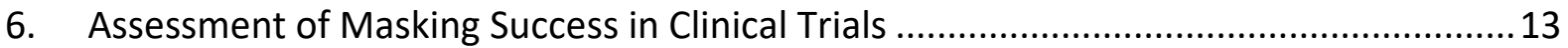

7. Reporting of Masking and Expectancy in Psychedelic RCTs .......................................15

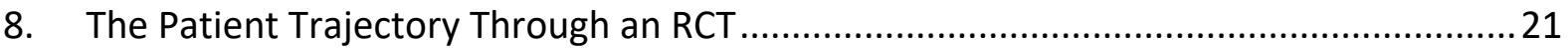

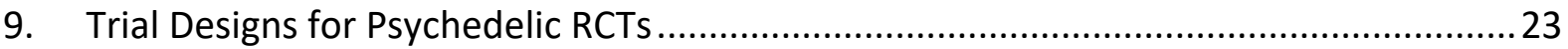

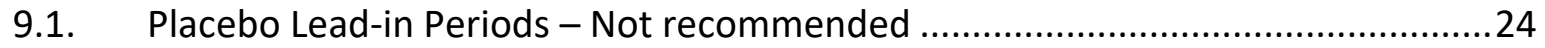

9.2. Sequential Parallel Comparison Design (SPCD) - Not recommended...................25

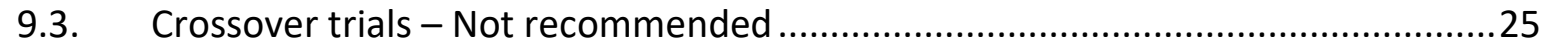

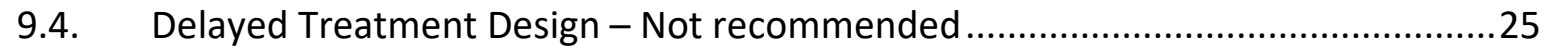

9.5. Parallel Groups Design with Active Comparator ...............................................25

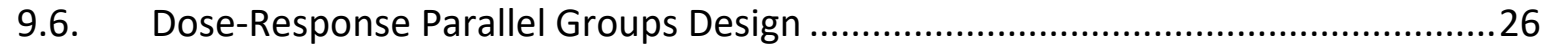

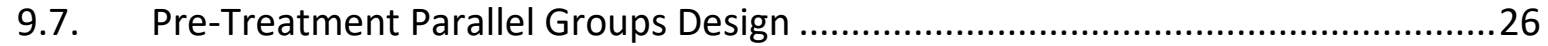

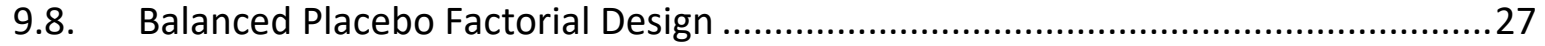

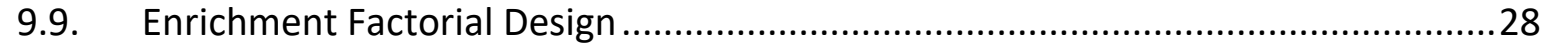

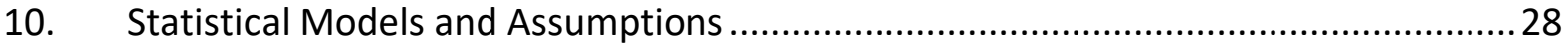

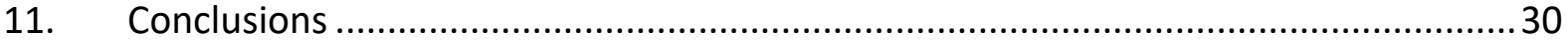

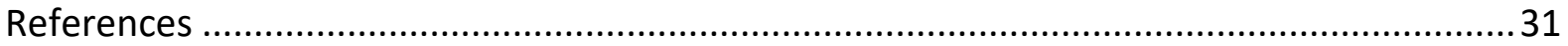




\section{Introduction}

The last twenty years has seen a surge of interest in the therapeutic use of psychedelic drugs for a range of psychiatric/mental health conditions. Psychedelic drugs used in this context represent a fundamental challenge to the modern evidence-based medicine system which is heavily focussed on gathering evidence of treatment efficacy through "gold-standard" randomised controlled trials (RCTs). A key principle of the RCT approach is that patients are allocated to groups under double-masked ${ }^{1}$ conditions, which help to prevent biases which may affect estimates of pre-defined outcome measures. Indeed, many of the outcome measures used in psychiatry are non-objective and therefore particularly vulnerable to various biases which will be described. While studies of psychedelic drugs can be masked in terms of their design, unless further steps are taken participants can usually discern to which condition they have been allocated to even when active placebos are used. This "unmasking" reduces the impact of masking on controlling bias and lessens the accuracy of treatmenteffect size estimation. As such, the evidence for efficacy obtained from therapeutic RCTs of psychedelic drugs where masking has clearly failed falls short of the evidence obtained in other areas of medicine.

In this paper it is argued that how standard clinical trial designs are applied to gather evidence for the efficacy of psychedelic drugs should be re-considered. This paper begins with a description of the randomised control trial and how it is used to establish causal relationships between treatments and outcomes by the formalism of the Rubin causal model. The historical evolution of the RCT and its design features are described along with the emergence of the first wave of psychedelic drug clinical trials. Following this is a discussion on the nature of expectancy effects in RCTs and how expectancy can be modified by experimental contingencies in an RCT. Next, the nature and importance of masking in RCTs is considered along with methods that can be used to measure the success of masking in RCTs. The state of the psychedelic trial literature since the 1990s is then subjected to several systematic reviews to examine the reporting of expectancy and masking in two sub-groups of studies: RCTs of ketamine in depression and serotonergic psychedelic trials of any design in mood disorders. A clear pattern emerges where the field has failed to measure, or at least report, masking success or pre-treatment participant expectancy. We conclude the paper by considering a number of clinical trial designs that are, and are not, appropriate for use in psychedelic RCTs as well as several statistical models that could be used to estimate treatment effects under different assumptions.

\section{Causal Inference and the Randomised Controlled Trial}

At their heart, clinical trials consist of experimental units of observation (participants), treatments and the evaluation of outcomes (see $[1,2]$ for comprehensive descriptions). The aim of the randomised controlled clinical trial is to establish the existence of a causal relationship between treatments and outcomes. In this regard it is worth considering the logic

\footnotetext{
${ }^{1}$ From here we take the modern terminology of referring to blinding as masking. This terminology is being more widely adopted to distinguish masking from studies in the visually impaired. Further, although we refer to double-masking, this terminology is best avoided in detailed trial reporting. Following CONSORT guidelines, the specific groups being masked should be specified, for example, participants and outcome assessors.
} 
behind making causal inferences from clinical trials within the formalism of Rubin's causal model $[3,4]$. Let $U$ be a population of units with $u$ denoting an individual unit and $Y$ be a response variable we will seek to explain, with $Y(u)$ being the response of an individual unit. Take a simple case in which there are two binary treatment options ( $t$ for treatment and $c$ for control) and let $S$ be a variable that indicates to which treatment a unit is exposed, hence $S(u)$ $=t \vee S(u)=c$. Notably, $Y$ is an attribute of $U$, whereas $S$ indicates exposure to a cause and hence $Y(u)$ must be measured at some time after exposure of $u$ to $S(u)$. Prior to exposure there are two potential states $Y$ could have been in the future, that is $Y_{t}$ or $Y_{c}$. Any unit could then take values $Y_{t}(u)$ and $Y_{c}(u)$. The causal effect of $t$ on $u$ is called the individual treatment effect (ITE) and can be defined by:

$$
I T E=Y_{t}(u)-Y_{c}(u)
$$

Importantly, of the two potential outcomes for any individual at any point in time $\left(Y_{t}(u)\right.$ and $\left.Y_{c}(u)\right)$, one is counterfactual and can never be observed - this is termed the fundamental problem of causal inference [3]. That is, at any time-point it is impossible to observe both $Y_{t}(u)$ and $Y_{c}(u)$ without making additional assumptions. Two approaches described by Holland [4] to overcome the fundamental problem of causal inference are to make assumptions of homogeneity or invariance. The assumption of homogeneity is that all units in a population would elicit the same treatment effect while the invariance assumption is that treatment effect would be the same at all times for a unit - regardless of previous events/exposures. These are unrealistic assumptions for many medical interventions, so the approach taken in clinical trials is a statistical approach, which is to attempt to quantify the average treatment effect (ATE) over a population of interest $U$. The ATE can be described as:

$$
A T E=E(I T E)=E\left(Y_{t}-Y_{c}\right)=E\left(Y_{t}\right)-E\left(Y_{c}\right)
$$

where $E$ represents the expected value. Notably, this approach does not assume that ITE is constant across $U$ (no homogeneity assumption). In terms of observed data in an experiment, a single response variable $\left(Y_{s}\right)$ is measured alongside our intervention to give the variable pair $\left(S, Y_{s}\right)$. Observed data then provide:

$$
\begin{aligned}
& E\left(Y_{s} \mid S=t\right)=E\left(Y_{t} \mid S=t\right) \\
& E\left(Y_{s} \mid S=c\right)=E\left(Y_{c} \mid S=c\right)
\end{aligned}
$$

But these conditional expected values need not be the same as $E\left(Y_{t}\right)$ and $E\left(Y_{c}\right)$. This is because $E\left(Y_{t}\right)$ is the average of all $u$ in $U$ whereas $E\left(Y_{t} \mid S=t\right)$ is the average over only those $u$ exposed to $t$ (and similarly for $c$ ). However, randomisation of a sufficient number of samples of $u$ to either $t$ or $c$ can make $S$ statistically independent to $Y_{s}$ such that it is reasonable that:

$$
E\left(Y_{t}\right)=E\left(Y_{t} \mid S=t\right)
$$

A further assumption of the Rubin causal model is the stable unit treatment value assumption (SUTVA) in which sampling of one individual is unaffected by the assignment of other individuals. In clinical trials the SUTVA assumption generally holds as individual cases are typically dealt with in isolation, however in group intervention situations, such as group therapy, this would become more complex and the SUTVA assumption might not hold. 
While the aim of the clinical trial is to evaluate the causal effect of treatments by the estimation of ATE, Deacon and Cartwright [5] point out a few key ways that ATE can be easily misinterpreted. Firstly, the ATE estimated for the trial sample does not apply to every member of the trial sample. Indeed, even if ATE $=0$ it is incorrect to state that the treatment does not have an effect in every unit in the trial sample - as it is not possible to estimate the counterfactual for each individual unit. Secondly, when heterogeneous populations are studied, the ATE in the trial is sample is more likely to differ from the population it is selected from. This is particularly true for small samples and it is also true that as sample size decreases the probability that the independence assumption is achieved through random sampling decreases - especially if there are many potential covariates of interest. Finally, the extent to which ATE is "true", that is, an accurate, unbiased estimator, it is only true for the trial sample. Even after meeting the internal validity criteria described above it is an open question as to how the effect size may apply to the general population. One should be particularly wary of this for the populations studied in psychedelic drug trials. Out of an appropriate abundance of caution given the powerful effects of the substances involved and to reduce potential confounders there are typically rigorous screening criteria applied to potential participants. These criteria, and self-selection / self-exclusion biases, may underlie our informal observation that the attrition rate in the steps leading up to participant randomisation in psychedelic trials is high. One could argue the higher this attrition rate, the less generalisable ATE becomes to the general population, as units in the trial will be more similar than they are in real life random samples of that population. The problem of external validity was not lost on the pioneering epidemiologist Sir Austin Bradford-Hill who stated "At its best a trial shows what can be accomplished with a medicine under careful observation and certain restricted conditions. The same results will not invariably or necessarily be observed when the medicine passes into general use." (cited in [6]).

\section{Brief History of the RCT and Psychedelic RCTs}

For causal inference to be made between treatments and outcomes, and for estimates of ATE to be unbiased, the experimentalist must control a number of potential biases. The goldstandard RCT developed through cumulative progress over the course of the 20th century [7] to reduce potential biases and strengthen causal inference in clinical research. In the 1920s, randomisation of participant groups to minimise selection bias became more common. Subsequently, Bradford-Hill introduced the notion of masking in the 1940s in the UK in a series of clinical trials investigating the antibiotic streptomycin for the treatment of tuberculosis [7, 8]. The innovations of Bradford-Hill were tremendously influential, and these standards were successively adopted into legislative frameworks. In the USA, the Kefauver-Harris Amendments to the Food, Drug, and Cosmetic Act were passed in 1962 and the RCT became the tool by which pharmaceutical manufacturers could demonstrate efficacy and safety to regulators. By 1970 it was a requirement of the FDA that new drug applications submit RCT results as part of their submissions [7] . Although not specifically defined, it was clear from Congressional directives that well-controlled studies should include "as a minimum, the use of control groups, random allocation of patients to control and therapeutic groups, and techniques to minimize bias" [9].

In a parallel history, investigations into the medical use of psychedelic drugs exploded in the 1950s following the discovery of the psychedelic properties of LSD by Albert Hoffman 
in 1943 [10]. Between 1950 and the mid-1960s there were more than a thousand clinical papers including results from 40,000 patients administered psychedelics [11]. Successive tightening of legislation, restricted access to the supply of pharmaceutical-grade psychedelic drugs and societal pressures meant the last NIMH project using LSD on human participants ended in 1968 [11]. Because psychedelic research in this era occurred as modern clinical trial methodology was developing, the trials rarely meet modern standards for RCT design and/or reporting. For example, in a modern systematic review of studies conducted in this era for the use of LSD to treat alcoholism, only 6 of 33 studies met modern criteria of randomisation / masking / outcome assessment [12]. Notably all of these studies happened late in the first psychedelic era (reported 1966-1970).

\section{Placebo Responses, Expectancy and Alliance}

According to the Oxford Dictionary, the word placebo has been in use since 1811 and was defined as "medicine given more to please than benefit a patient" (Gaddum cited in[13]). Placebos have been well-known to, and used by, physicians for centuries (see [14]) but it was with the development of the RCT that the placebo response began to be considered in its modern context within the framework of biomedical science. The placebo response refers to the observed changes in symptoms in those participants who have been randomised to a placebo control group in an RCT. The placebo effect is the therapeutic effect of receiving a treatment that is not caused by any inherent properties of the treatment or due to natural progress of the disease [15]. In a landmark paper in 1953, Beecher [13] first attempted to quantify the placebo response. He observed across 15 trials in various conditions that $~ 35 \%$ of patients were satisfactorily treated by treatment with a placebo. In a controversial metaanalysis conducted in 2000, Hrobjartsson and Gotzche [16] assessed trials which included a placebo arm and a no-treatment arm and found that, in trials with objective and/or binary outcomes, placebo groups showed no significant effects over and above those seen in the notreatment arm. However, significant effects did emerge for those participants in placebo arms over those in no-treatment arms where continuous, subjective outcome measures were used - such as those used in the assessment of pain. It has been argued that the approach of Hrobjartsson and Gotzche [16] likely underestimates the placebo effect in clinical practice; in RCTs there is doubt about whether a participant will receive a treatment or a placebo whereas in clinical practice active treatment is always given. Underestimation may also be driven by the inability to distinguish between those participants in the placebo groups who believed they had received the treatment and those who did not [17]. As will be shown in this section, belief and expectancy are important mediators of the placebo effect. A number of commentaries [18-20] more fundamentally criticise the attempt of Hrobjartsson and Gotzche to ascertain the size of "the" placebo effect by using meta-analytical techniques. There is no singular placebo effect to be quantified, rather the size of the placebo effect in any particular clinical trial will be modified by the specific experimental contingencies employed in each trial [18-21].

To understand the nature of the placebo effect Miller and Rosenstein [17] usefully discuss four types of healing; active-treatment $(A T)$ induced healing, placebo-induced healing, healing induced by clinician-patient interaction and spontaneous natural healing $(\mathrm{NH})$. The placebo effect $(P E)$ is often defined as a combination of placebo-induced healing and healing induced by clinical-patient interaction as these are difficult to disentangle. Turner et al. [22] 
defined the placebo effect as being composed of the non-specific effects of treatment including factors such as "physician attention, interest, and concern in a healing setting; patient and physician expectations of treatment effects; the reputation, expense, and impressiveness of the treatment; and characteristics of the setting that influence patients to report improvement". Natural fluctuations in disease course potentially confound both treatment and control groups of psychedelic trials. This can include spontaneous healing, but also potentially regression to the mean where participants might be most likely to volunteer for extreme interventions at their time of greatest clinical need. The confidence from which one can distinguish signal from noise in treatment of an individual over and above natural history [23] is enhanced with increased baseline stability of the disease in the pre-treatment period relative to the duration of the treatment period. In our analysis of recent psychedelic trials (see Section Reporting of Masking and Expectancy in Psychedelic RCTs) baseline stability of disease course was rarely characterised.

It is important to note that the control group in the parallel groups design as described with the Rubin Casual Model $[3,4]$ measures the placebo response but not the causal placebo effect as it is confounded by spontaneous healing effects. In order to distinguish the placebo effect from spontaneous healing a no-treatment control group is required [17]. If such a group (let $n=$ no treatment) is included in an RCT, then one can extend the counterfactual framework [24] of the Rubin Causal Model to estimate an Average (causal) Placebo Effect $(A P E)$ as:

$$
A P E=E(I P E)=E\left(Y_{c}-Y_{n}\right)=E\left(Y_{c}\right)-E\left(Y_{n}\right)
$$

While inclusion of an additional no-treatment group might be useful in order to measure an $A P E$, the estimation would only be unbiased to the extent that adequate masking is maintained (see Section Assessment of Masking Success in Clinical Trials).

It has been shown that the knowledge that one is participating in a clinical trial can influence the size of an estimated APE and also ATE. If the RCT is the "gold standard" trial then consider what Kaputchuk [25] calls the "platinum standard" trial - where both clinicians and patients are actually unaware that they are taking part in an RCT. Although ethical standards of informed consent now forbid this type of deception, there are some historical examples that can be drawn upon. In one study of insomnia patients [26], all patients were being given dummy sleeping pills, with half the participants unaware they were even in a trial. The other half of the participants who knew they were in a trial and thought they could be getting either placebo or active treatment, showed less improvement than those patients who were unaware they were in a trial at all and received a placebo by deception. That is, in this scenario, knowledge of being in an RCT decreased the placebo response. In a complementary example [27], patients received either naproxen or placebo in a crossover trial for cancer pain. One group of patients were unaware of the experiment while the other group were aware of the design after giving informed consent to participate. In this case both the placebo and active treatments in the group who gave informed consent were more effective than the same treatments in the group of patients who had no knowledge of the RCT. Further, the placebo response in the informed group was actually greater than the active response in the uninformed group. Taken together, these experiments show not only that the process of informed consent can modify the placebo response but that the direction and magnitude of the placebo response depends on experimental contingencies. 
Consider the healing components as per Miller and Rosenstein [28] that contribute to a three arm experiment under the Rubin Causal Model where $\boldsymbol{N}=$ no treatment group, $\boldsymbol{C}=$ control (placebo) group and $\boldsymbol{T}=$ treatment group then under a model of linear additivity of therapeutic effects:

$$
\left[\begin{array}{l}
\boldsymbol{N} \\
\boldsymbol{C} \\
\boldsymbol{T}
\end{array}\right]=\left[\begin{array}{ccc}
N H_{n} & 0 & 0 \\
N H_{c} & P E_{c} & 0 \\
N H_{t} & P E_{t} & A T_{t}
\end{array}\right]
$$

From this, APE is defined by row subtraction $(\boldsymbol{C}-\boldsymbol{N})$ and ATE by row subtraction $(\boldsymbol{T}-\boldsymbol{C})$. However, these subtractions only hold under the assumption that $N H_{n}=N H_{c}=N H_{t}$ and $P R_{c}=P R_{t}$. The first assumption is reasonable under randomisation conditions, however, as the platinum standard trials [25] discussed previously demonstrate, this latter equivalency need not be the case and with the potential for unmasking in psychedelic trials this is even more uncertain (see Section Reporting of Masking and Expectancy in Psychedelic RCTs). Previously, interactive models for combining the effects of $A T$ and $P E$ have been proposed $[29,30]$. We note that for $P R_{c} \neq P R_{t}$ then $\boldsymbol{T}=N H_{t}+P E_{t}+A T_{t}$ and for an interactive model $\boldsymbol{T}=$ $N H_{t}+P E+A T_{t}+\mathrm{d} P E A T_{t}$ (where $d$ is an interaction term) then model comparison gives $P E_{t}=P E+\mathrm{d} P E A T_{t}$ which are functionally equivalent for the experimentalist. Whether the additive model for psychedelic RCTs holds is untested, but proponents of psychedelic medicine have long held that both "set and setting" are essential components in the healing process [31] suggesting an interactive model. Strassman [32] has gone further arguing that the effects of psychedelics are entirely due to its amplification of the placebo response. That is $\boldsymbol{C}=P E_{t}$ and $\boldsymbol{T}=e P E_{t}$ (e could be either a constant or a function). In Section Trial Designs for Psychedelic RCTs some alternative designs are considered that might help to separate specific and non-specific (or set and setting) factors of psychedelic therapy. However, even within Strassman's framework to demonstrate efficacy is still necessary to show that $\hat{e}$ for a psychedelic intervention is significantly different to $\hat{e}$ for a (successfully masked) placebo.

What other factors, beside the knowledge one is in an RCT might influence the placebo effect in an RCT? In a study examining the placebo effect in acupuncture, Kaptuchuk et al [33] separated the placebo effect into three components: a patient's response to observation and assessment, response to therapeutic ritual, and response to patient-clinician interaction. They found that all three elements contribute to the placebo effect with patient-clinician interaction being the largest contributor. Drawing on common factors theory of psychotherapy, Gukasyan and Nayak [34] identify four factors relevant to psychedelic medicine -1 ) the therapeutic relationship between patient and therapist, 2) the healing setting, 3) the rationale, conceptual scheme, or myth underlying the treatment and 4) the ritual of the treatment itself. Many of these contextual factors could be manipulated in psychedelic designs to test their influence (see [35] and Section Trial Designs for Psychedelic $\underline{\mathrm{RCTs}}$ ). Physical features of the treatment such as its appearance, route of administration, price, brand and expected dose can all modify the placebo effect in mood disorders [36].

A key contributor to the placebo response in RCTs is expectancy - primarily response expectancy. Response expectancy [36] refers to patients' predictions/beliefs of their own nonvolitional response to treatment whereas (less relevant in this context) stimulus expectancies refer to anticipation of external events. Zilcha-Mano et al. [37] argue that expectancy, similar to alliance, can be composed of trait- and state-like components. The trait-like component reflects patients' individual differences in levels of expectancy whereas 
the state-like component refers to changes that occur over the course of treatment. Expectancy is known to influence the estimation of ATE in RCTs of standard antidepressants. A meta-analysis [38] of RCTs of antidepressants compared placebo-controlled trials to activecomparator trials - where another approved antidepressant is used as a comparator condition. It was found that the overall odds of an antidepressant response being observed is significantly higher in active-comparator trials (odds ratio $=1.79$ ). A reasonable explanation of this is that in active-comparator trials patients will have higher expectancy of receiving an active treatment. Further, a meta-regression approach [39] found that the greater the probability of receiving a placebo, the lesser the placebo response. Similarly, a meta-analysis [40] of 1504 patients undergoing psychotherapy in 19 studies found patient pre-treatment expectancy of positive outcome predicted treatment efficacy, albeit relatively weakly. In the psychedelic research field, a recent microdosing study demonstrated that positive expectancy scores at baseline predicted improvements of well-being during the trial [41].

One existing tool that can be used to measure expectancy is the six-item Credibility/Expectancy Questionnaire (CEQ) which has been shown to have high internal consistency and test/re-test reliability [42, 43]. In an antidepressant trial, Rutherford et al [44] administered the CEQ as a simple two-item scale suitable for antidepressant trials. Item 1 uses the question, "At this point, how successful do you think this treatment will be in reducing your depressive symptoms?" and is rated on a 9-point Likert scale from not at all successful (1) to very successful (9). Item 2 uses the question, "By the end of the treatment period, how much improvement in your depressive symptoms do you think will occur?" and is rated on an 11-point Likert scale with anchors at $0 \%$ and $100 \%$. Rutherford et al [44] used the sum of these two questions to provide an overall CEQ score and found that higher baseline expectancy of improvement correlated with improved treatment outcomes. In a prospective RCT designed to manipulate expectancy, Rutherford et al [45] randomised patients with a 1:1 allocation ratio to either an open-label antidepressant intervention or to a parallel-groups trial. Patients were informed of which group they were in with open-label patients told they would receive the active intervention while those in the parallel groups trial were told they could either be in an active or a placebo group. Expectancy was measured before and after randomisation and it was found that expectancy of a positive outcome significantly improved in the open-label group post-randomisation but not in the parallel-group - indicating successful experimental manipulation of the state-like component of response expectancy. Following an 8-week course of antidepressants, ATE was found to be larger in the open-label group compared to both arms of the parallel groups trial with post-randomisation expectancy acting as a mediator of ATE [45]. Not only is this trial an elegant experimental demonstration of how expectancy can be manipulated to alter ATE, it serves as a demonstration of how novel RCT designs can be used to decouple expectancy from ATE, and how expectancy can be measured over time. Another standardised scale that could be used is the Stanford Expectation of Treatment Scale (SETS) [46] which captures some different domains to CEQ. Ultimately however, psychedelic medicine may benefit from the development of a purposebuilt expectancy scale given the unique features of these studies.

Although most studies examining the potential use of ketamine in depression to date (See Section Reporting of Masking and Expectancy in Psychedelic RCTs) have not incorporated psychotherapy (but note $[47,48]$ ), the model of psychedelic medicine being adopted for classical psychedelics such as LSD/psilocybin incorporates a strong element of psychotherapy. Generally in psychotherapy, the development of a strong working relationship (therapeutic alliance) between patient and therapist [37] has a crucial effect on the success of treatment, 
with a meta-analysis including 30,000 patients from 295 studies demonstrating an effect size of $d=0.579$ [49]. Indeed, it has been shown that placebo responses (to acupuncture) are enhanced when practitioners have a warm, friendly manner compared to a neutral manner [33]. Consistent with the notion of therapeutic alliance, meta-analyses of RCTs of standard antidepressants $[50,51]$ have shown an increased number of follow-up visits accounts for $\sim 40 \%$ of the placebo response in those allocated to placebo arms [50]. Indeed, increased visit numbers are thought to partly account for the increase in placebo response size that has been found in RCTs of antidepressants over the last 30 years [52]. Measurement of patientpractitioner therapeutic alliance can be performed using a number of well-established psychometric tools such as the CALPAS, HAQ, HAQII and WAI [49] which could easily be incorporated in a longitudinal manner [37] in psychedelic studies that incorporate elements of psychotherapy. Several studies now suggest that alliance can be conceptually separated into trait- and state-like components of which the modifiable state-like components relate to therapeutic outcome [37].

\section{Masking in Trials of Psychedelic Drugs}

The International Council for Harmonisation of Technical Requirements for Registration of Pharmaceuticals for Human Use (ICH) [53] guidelines summarise the role of masking in clinical trials: "Blinding or masking is intended to limit the occurrence of conscious and unconscious bias in the conduct and interpretation of a clinical trial arising from the influence which the knowledge of treatment may have on the recruitment and allocation of subjects, their subsequent care, the attitudes of subjects to the treatments, the assessment of end-points, the handling of withdrawals, the exclusion of data from analysis, and so on. The essential aim is to prevent identification of the treatments until all such opportunities for bias have passed." (pg. 11).

One important issue related to psychedelic drug trials is that while trials can be double-masked "by design", retrospective examination of the maintenance of masking is rarely reported and when it is it often reveals that masking was not maintained. For example, take our recent crossover-RCT assessing antidepressant responses to ketamine $(0.43 \mathrm{mg} / \mathrm{kg})$ which included the active placebo remifentanil $(1.7 \mathrm{ng} / \mathrm{ml})$ [54]. For reference, a targetcontrolled infusion of $1.7 \mathrm{ng} / \mathrm{ml}$ is a fairly sedative dose - with much higher levels causing increasing frequency of apnoea in participants. At the end of the trial, 27 participants were asked which study day they thought was which prior to being unmasked. Participants guessed correctly $88 \%$ of the time (24/27) and scored their confidence with an average of $7.67 / 10$ $(S D=2.12)$. The other $12 \%$ guessed incorrectly with an average $9 / 10$ confidence $(S D=1)$. The most common reason given by participants for a correct guess was psychoactive symptoms, followed by stronger symptoms overall, and then the magnitude of the antidepressant response to ketamine. The reason for incorrect guesses appeared to be driven by mistaken expectations of how the drugs would feel [54]. Similarly, the masked outcome assessor guessed correctly $88.5 \%$ of the time and scored their confidence with an average 6.42/10 $(S D=2.54)$. These data suggest that for our trial, breaking of masking was widespread.

We contend that the estimation of ATE in all psychedelic clinical trials is overestimated due to unmasking effects. Given the obvious psychoactive effects of psychedelic drugs, those in an active intervention group likely know they have received the treatment and may show greater treatment response due to expectancy effects. Those participants that receive a 
placebo intervention may well know they have received the placebo and disappointment may decrease their placebo response. Added together, these tendencies would increase the overall estimate of ATE. Consistent with this, a previous systematic review of medical RCTs examined studies which had both masked and non-masked trial arms along with subjectivelyassessed treatment outcomes and demonstrated that effect sizes can be exaggerated by 0.56 standard deviations in unmasked trials [55]. Similarly, meta-epidemiological analyses have shown that studies that use subjective outcomes to measure ATE and that lack, or have unclear, double-masking procedures demonstrate a $23 \%$ increase in effect size [56]. In a meta-epidemiological analysis of osteoarthristis RCTs, it was found that effect sizes were significantly reduced in masked versus non-masked trials [57]. Application of the Cochrane Risk of Bias Tool (RoB-2 [58]) to psychedelic trials is likely to find at least moderate risk of bias in terms of "deviations from the intended interventions" and "effect adhering to intervention to categories". A previous Cochrane review on the use of ketamine in treatment-resistant depression raised concerns around the adequacy of masking in these studies [59]. In antidepressant trials it has been shown that when active placebos are used to mimic the side effects of active treatment, effect sizes tend to be more modest than generally reported suggesting that unmasking may inflate ATE estimation in antidepressant trials [60].

One potential counterargument to the importance of maintaining masking in trials is that the clinical benefits of psychedelics are so large in terms of effect sizes that they outweigh the needs for masked trials, indeed RCTs at all. This is not a new idea in medical practice. For example, Galasziou et al. [23] provide a number of examples where RCTs have not been not needed for treatments to be accepted into medical practice due to effect sizes being dramatically large. Some examples include de-fribillation for ventricular fibrillation, insulin for diabetes, and the effects of anaesthesia. Notably, of the sixteen examples provided by Galasziou et al. [23] all had clear objective outcome measures. Moreover, the effects of these interventions are so large that it would be neither ethical to conduct RCTs or plausible to mask them, so dramatic are the intervention effects. Philip's paradox states that the more potent a therapeutic treatment the less likely its efficacy can be shown in a double-masked trial. That is, the more powerful the treatment the less likely the patient (and observers) can be masked and the more likely biases will affect the study [61]. This argument rests on the premise that an observed effect size will be comfortably larger than the purported effects of all potential confounders [62]. But are the effect sizes in psychedelic trials so large? In a trial of ketamine for depression with midazolam as a placebo control, $28 \%$ of participants assigned to the placebo condition were classified as responders - with a greater than $50 \%$ reduction in depression scores [63]. Similarly, in our study which used remifentanil as an active control for ketamine, $10 \%$ of participants were classified as responders after the placebo intervention [64]. These relatively large placebo effects seen with psychedelic trials, combined with the subjective nature of the outcome measures, make it difficult to rely on this 'large-enough' effect size argument. By comparison, the outcomes of the interventions mentioned by Galasziou et al [23] involve clear objective indicators such as mortality.

To solve Philip's paradox for clinical trials, Howick [62] considers the nature of what a confound is. Generally, in order for a variable to be considered a confounder in a clinical trial, the variable must affect the outcome, be unequally distributed across groups and not be on the causal pathway between treatment and response [62, 65, 66]. Howick distinguishes two types of unmasking - benign unmasking which is caused by the effects of the intervention on the target disorder and malicious unmasking which is caused by side effects of the intervention. Psychedelic drugs create a rich array of psychological and 
physiological experiences and it would be difficult to argue which were incidental to any effects required for clinical efficacy. As we have seen in the qualitative reporting from our ketamine trial the primary reason given by participants for drug identification was the psychoactive effects of the drugs, not their beliefs about antidepressant efficacy. Howick [62] argues that in order to serve its function, double-masking must have successfully controlled malicious masking. In subsequent sections we will consider various trial designs that might aid in reducing de-masking effects in psychedelic trials, but first methods for evaluating masking success in clinical trials will be considered. We end this section by noting that if one does not believe that psychedelic trials could ever be adequately masked then it becomes unclear what the point of an RCT for psychedelics would be? Such a study would always be confounded, and the comparator control group would have no utility. If masking cannot be successful then running single group open-label trials would be more useful for accurately characterising treatment response given resource constraints, while still allowing examination of the effects of baseline covariates such as expectancy, however, this would preclude the ability for causal inference regarding ATE to be made.

\section{Assessment of Masking Success in Clinical Trials}

The CONSORT 2010 statement [67] does not recommend that investigators report on the efficacy of masking of participants in trials - only that any explicit breaks in masking are reported. This was a clear difference from the CONSORT 2001 [68] statement which recommended that the success of masking be evaluated. Even with the earlier CONSORT recommendation, masking success was evaluated and reported in clinical trials infrequently. In a meta-analysis of medical and psychiatric RCTs, Fergusson et al. [69] evaluated the number of trials that assessed masking. For psychiatric trials, only 8/94 assessed masking success with four reporting sub-optimal masking. Only two of these measured masking in outcome assessors. Similarly, Hrobjartsson et al. [70] inspected 1599 medical RCTs from the Cochrane Register of Clinical Trials and found only 31 reported tests for the success of masking. On being contacted, a subset of authors (12\% out of 200 ) reported they had conducted but not reported measurements of masking effectiveness. In response to these papers, Sackett [71, 72] pointed out there is uncertainty around whether responses to masking assessment questions reflect potential failure of masking or accurate assumptions of the intervention's clinical effects. Senn [73] further argued that from one perspective the point of a clinical trial is for patients to become unmasked due to efficacy, as long as the unmasking is not incidental to efficacy. Such arguments were followed by the removal of masking assessment from the CONSORT 2010 statement [67]. However, the arguments of Sackett and Senn refer to benign rather than malicious unmasking. While these arguments are relevant to medical drug interventions like the RCTs of aspirin as alluded to by Sackett [71] they are less relevant to psychedelic drugs with their clear psychoactive effects. Notably, Sackett does not suggest that de-masking effects be ignored - rather he suggests that specific confounders that might cause de-masking are measured and evaluated in a controlled fashion. However, Sackett's approach relies on there being no unknown confounders and accurate estimation of measured confounders which is not realistic - especially for psychiatry where underlying mechanisms are not completely understood. As Howick [62] notes there is no reason that a trial cannot combine both by measuring potential confounders and the success of masking. 
There is no standard approach for assessing masking efficacy. One method is to allow participants to guess which arm of the trial they are in as a categorical response variable : "drug", "placebo", "don't know" [74]. Another variation is to use a five-point Likert scale including a "don't know" option which adds a degree of uncertainty [74]. For categorical responses answers can be summarised in a contingency table such as Table 1.

Table 1: Response contingency table for participants guesses regarding treatment allocation

\begin{tabular}{|c|c|c|c|c|}
\hline Assignment & \multicolumn{3}{|c|}{ Response } & Total \\
\hline & Drug & Placebo & DK & $n_{1, .}$ \\
\hline Drug & $n_{1,1}$ & $n_{1,2}$ & $n_{1,3}$ & $n_{1, .}$ \\
\hline Placebo & $n_{2,1}$ & $n_{2,2}$ & $n_{1,3}$ & $\mathrm{~N}$ \\
\hline Response & $n_{., 1}$ & $n_{., 2}$ & $n_{., 3}$ & \\
\hline
\end{tabular}

Conditional probabilities $\left(P_{\mathrm{j} \mid \mathrm{i}}\right)$ can be assigned to each cell letting $j$ refer to columns (responses) and $i$ refer to rows (treatment assignment) $\left(P_{j \mid i}=n_{j, i} / \sum_{j} n_{j, i}\right)$. Two proposed masking indexes to estimate the overall effectiveness of masking from these metrics with extensions for Likert-scale data are the James Blinding Index ( $\left.\mathrm{Bl}_{\text {James }}\right)$ [75] and the Bang Blinding Index ( $\left.\mathrm{Bl}_{\text {Bang }}\right)$ [74] . The James Blinding index [75] is calculated as:

$$
\begin{aligned}
& B I_{\text {James }}=\frac{\left\{1+P_{D K}+\left(1-P_{D K}\right) * K_{D}\right\}}{2} \\
& \text { where } K_{D}=\frac{P_{D o} P_{D e}}{P_{D e}} \\
& P_{D O}=\sum_{i=1}^{2} \sum_{j=1}^{2} \frac{w_{i j} P_{i j}}{1-P_{D K}} \\
& \text { and } P_{D e}=\sum_{i=1}^{2} \sum_{j=1}^{2} \frac{w_{i j} P_{. j}\left(P_{i .}-P_{i 3}\right)}{\left(1-P_{D K}\right)^{2}}
\end{aligned}
$$

Weights $\left(w_{i j}\right)$ are assigned such that 0 is assigned for correct guesses, 0.75 for incorrect guesses and 1 for "don't know" responses. Bl James $_{\text {can }}$ range between 0 and 1 . When all responses are correct, and masking has failed $\mathrm{Bl}_{\mathrm{James}}=0$ and when all responses are don't know $\mathrm{Bl}_{\mathrm{James}}=1$ indicating completely successful masking. $\mathrm{B} \mathrm{I}_{\mathrm{James}}=0.5$ would indicate random answers. In practice, if the confidence interval (see [75]) of the estimate contains values $<0.5$ then masking is said to have failed for the trial. Bang et al [74] introduced an alternative Blinding Index ( $\left.\mathrm{Bl}_{\text {Bang }}\right)$ which allowing masking assessment to be measured for each arm of a trial.

$$
\begin{gathered}
B I_{\text {Bang }(i)}=\left(2 r_{i \mid i}-1\right) \times \frac{n_{i 1}+n_{i 2}}{n_{i 1}+n_{i 2}+n_{i 3}} \\
\text { where: } r_{i \mid i}=\frac{P_{i \mid i}}{\left(P_{1 \mid i}+P_{2 \mid i}\right)}
\end{gathered}
$$

In each arm of the trial an estimate $B I_{B a n g}$ with range of $-1 \leq\left. B\right|_{B a n g} \leq 1 . A B I_{B a n g}$ value of 0 indicates chance responding (masking) while a positive value indicates unmasking and a negative value incorrect guessing (see [74] for variance estimator calculation). For psychedelic 
trials it seems intuitive that masking may not be symmetrical between the trial arms, making $\mathrm{Bl}_{\text {Bang }}$ a more appropriate index to use. However, it may be desirable to better capture the degree of uncertainty in each participant rather than having a single tertiary variable for the trial as a whole. A simple visual analogue scale (VAS) with end anchors at placebo and active with a middle anchor at "don't know" might be useful as a covariate in the analysis of individual outcomes.

When assessing de-masking an important consideration is when after the intervention to perform this assessment. While it is perhaps intuitive to assess masking at the end of the trial, if some unmasking reflects speculations about efficacy $[71,73]$ then masking assessment performed earlier may be more appropriate. We would suggest that masking assessment could be performed relatively soon after a dose of psychedelic but before assessment of outcomes and before participants begin to self-perceive potential treatment effects. In that way the assessment would focus on malicious confounding effects rather than estimation of efficacy. One could potentially assess masking at multiple time-points to assess the trajectory of de-masking. For example, in an RCT examining water treatment units in houses, Rees et al. [76] measured participants' guesses as to group allocation sequentially through the trial. They found that $31 \%$ of participants changed their belief allocation across the duration of the trial - an effect that would be missed from gathering a single time-point measurement of belief allocation. One concern with repeated measurements is that drawing attention to the issue may create a response bias [77]. Another important issue is how de-masking is operationalised practically. Although responses can be gathered verbally, social desirability biases and the impact of experiments covertly cueing their beliefs provide justification for computerised assessment.

\section{Reporting of Masking and Expectancy in Psychedelic RCTs}

In order to understand the state of the literature regarding the measurement of expectancy, de-masking and alliance in psychedelic trials, we conducted several systematic reviews. Firstly, we examined placebo controlled RCTs of ketamine for the treatment of major depressive disorder since a relatively large number of trials exist in this area and there are recent systematic reviews of this topic $[78,79]$. Secondly, we searched for trials of classical serotonergic psychedelics. Given there were relatively few trials we conducted one search for RCTs and one for open-label/other designs. Details of the search strategies used and PRISMA flowcharts are given in Supplementary Materials.

Tables 2-4 reveal that of the 43 included studies none had measured pre-treatment expectancy of participants. For ketamine RCTs (Table 2) of depression five trials measured masking with three providing quantitative data, although none used existing masking indexes as described in Section Assessment of Masking Success in Clinical Trials. Of these, only one reported maintenance of masking. For other psychedelic RCTs (Table 3), three out of six trials reported on participant masking, with none demonstrating successful masking. Two of the remaining trials reported rater masking, with only one reporting a degree of success, assessed by whether raters could guess trial design. None of the 43 trials considered described any assessment of patient-therapist alliance. Fourteen trials reported more than one baseline assessment - which would allow an analysis of disease trajectory - typically obtained during 
participant screening. Interestingly, the majority of trials did discuss that their analyses were limited by the potential for de-masking. Some of these more qualitative concerns are detailed in Supplementary Materials. In summary, these systematic reviews demonstrate that existing psychedelic RCTs have failed to measure the effects of participant expectancy and therapeutic alliance. Furthermore, only a minority of studies reported a masking assessment, with no attempts at a formal statistical analysis, and all but one reporting masking failure. 
Table 2: Summary of double-masked RCTs investigating the use of ketamine in depressive disorders

\begin{tabular}{|c|c|c|c|c|c|c|c|c|}
\hline Study & Diagnosis & Dosing \& RoA & Placebo & $\begin{array}{l}\text { Mono/ } \\
\text { Adjunct }\end{array}$ & $\begin{array}{c}\text { Primary clinical outcome } \\
\text { measurement }\end{array}$ & $\begin{array}{c}\mathrm{N} \\
\text { (per group) } \\
\end{array}$ & $\begin{array}{c}\text { Expect } \\
.\end{array}$ & Masking \\
\hline $\begin{array}{l}\text { Arabzadeh et al. } 2018 \\
\text { [80] }\end{array}$ & MDD & $50 \mathrm{mg}$ q.d, $\mathrm{PO}$ & Inact. & Adjunct & HDRS at baseline, 2, 4, 6 wks & $\begin{array}{l}\text { Ket. }=41 \\
\text { Placebo }=40\end{array}$ & $x$ & $x$ \\
\hline $\begin{array}{l}\text { Berman et al., } 2000 \\
\text { [81] }\end{array}$ & MDD & $0.5 \mathrm{mg} / \mathrm{kg}, \mathrm{IV}$ & Inact. & Mono. & $\begin{array}{l}\text { HDRS at baseline, } 80,230 \mathrm{~min}, 24, \\
48,72 \mathrm{hrs}\end{array}$ & 7 (cross-over) & $x$ & $\begin{array}{l}\checkmark \text { No formal report; in-text mention that } \\
\text { masking was unsuccessful. }\end{array}$ \\
\hline $\begin{array}{l}\text { Burger et al., } 2016 \\
\text { [82] }\end{array}$ & Suicidality & $0.2 \mathrm{mg} / \mathrm{kg}, \mathrm{IV}$ & Inact. & Mono. & $\begin{array}{l}\text { BSS at screening, baseline, } 40,80 \text {, } \\
120420 \mathrm{~min} \text {, discharge, } 2 \mathrm{wks}\end{array}$ & $\begin{array}{l}\text { Ket. }=3 \\
\text { Placebo }=7\end{array}$ & $x$ & $x$ \\
\hline $\begin{array}{l}\text { Canuso et al., } 2018 \\
{[83]}\end{array}$ & MDD & $\begin{array}{l}84 \text { mg twice } \\
\text { weekly } \\
\text { Intranasal }\end{array}$ & Inact. & Mono. & $\begin{array}{l}\text { MADRS at baseline, 4, } 24 \text { hrs, } 25 \\
\text { days }\end{array}$ & $\begin{array}{l}\text { Esket. }=35 \\
\text { Placebo }=31\end{array}$ & $x$ & $x$ \\
\hline Cao et al., 2018 [84] & MDD & $\begin{array}{l}0.2 \text { or } 0.5 \mathrm{mg} / \mathrm{kg} \text {, } \\
\text { IV }\end{array}$ & Inact. & Mono. & $\begin{array}{l}\text { HDRS at baseline, } 40,80,240 \mathrm{~min}, \\
1,3,4,5,6,7,14 \text { days }\end{array}$ & $\begin{array}{l}\text { Ket. }=37 \\
\text { Placebo }=18\end{array}$ & $x$ & $x$ \\
\hline Chen et al., 2018 [85] & MDD & $\begin{array}{l}0.2 \text { or } 0.5 \mathrm{mg} / \mathrm{kg} \text {, } \\
\mathrm{IV}\end{array}$ & Inact. & Adjunct & $\begin{array}{l}\text { HDRS at baseline, 40, 80, 120, } 240 \\
\text { min, } 1 \text { day }\end{array}$ & $\begin{array}{l}\text { Ket. }=16 \\
\text { Placebo }=8\end{array}$ & $x$ & $x$ \\
\hline Daly et al., 2018 [86] & MDD & $\begin{array}{l}28 / 56 \text { / } 84 \text { mg } \\
\text { twice weekly, } \\
\text { Intranasal }\end{array}$ & Inact. & Mono. & MADRS at baseline, $2,8,9,15$ days & $\begin{array}{l}\text { Esket. = } 33 \\
\text { Placebo }=33\end{array}$ & $\mathrm{x}$ & $x$ \\
\hline $\begin{array}{l}\text { Diazgranados et al., } \\
2010 \text { [87] }\end{array}$ & $\begin{array}{l}\text { Bipolar } \\
\text { depression }\end{array}$ & $0.5 \mathrm{mg} / \mathrm{kg}$, IV & Inact. & Adjunct & $\begin{array}{l}\text { MADRS at screening, baseline, } 40 \text {, } \\
80,110,230 \mathrm{~min}, 1,2,3,7,10,14 \\
\text { days }\end{array}$ & 13 (cross-over) & $x$ & $x$ \\
\hline $\begin{array}{l}\text { Domany et al., } 2019 \\
\text { [88] }\end{array}$ & Suicidality & $0.2 \mathrm{mg} / \mathrm{kg}, \mathrm{IV}$ & Inact. & Mono. & $\begin{array}{l}\text { C-SSRS at baseline, } 15,30,60,90 \text {, } \\
120,180,240 \mathrm{~min}, 1,2,3,7,14 \\
\text { days. }\end{array}$ & $\begin{array}{l}\text { Ket. }=9 \\
\text { Placebo }=9\end{array}$ & $x$ & $x$ \\
\hline $\begin{array}{l}\text { Downey et al., } 2016 \\
\text { [89] }\end{array}$ & MDD & $0.5 \mathrm{mg} / \mathrm{kg}, \mathrm{IV}$ & Inact. & Mono. & BDI at baseline, 1,7 days & $\begin{array}{l}\text { Ket. }=21 \\
\text { Lan. }=20 \\
\text { Placebo }=19\end{array}$ & $x$ & $x$ \\
\hline Fava et al., 2018 [90] & MDD & $\begin{array}{l}0.1 / 0.2 / 0.5 / \\
1.0 \mathrm{mg} / \mathrm{kg}, \mathrm{IV}\end{array}$ & Midaz. & Adjunct & $\begin{array}{l}\text { HDRS at baseline, 1, 3, 5, 7, 14, } 30 \\
\text { days }\end{array}$ & $\begin{array}{l}\text { Ket. }=80 \\
\text { Midaz. }=19\end{array}$ & $x$ & $\begin{array}{l}\checkmark \text { Unmasking at higher doses; \% correct } \\
\text { guesses (Raters, Participants): Placebo } \\
(42,37) ; 0.1 \mathrm{mg}(50,56) ; 0.2 \mathrm{mg}(55,45) ; \\
0.5 \mathrm{mg}(11,77) ; 1.0 \mathrm{mg}(95,95)\end{array}$ \\
\hline $\begin{array}{l}\text { Fedgchin et al., } 2019 \\
\text { [91] }\end{array}$ & MDD & $\begin{array}{l}56 \text { / } 84 \text { mg b.i.d, } \\
\text { twice weekly, } \\
\text { Intranasal }\end{array}$ & Inact. & Adjunct & $\begin{array}{l}\text { MADRS at } 4 \text { weeks prior, baseline, } \\
2,8,15,22,28 \text { days }\end{array}$ & $\begin{array}{l}\text { Esket. }=229 \\
\text { Placebo }=113\end{array}$ & $x$ & $x$ \\
\hline $\begin{array}{l}\text { Grunebaum et al., } \\
2017 \text { [92] }\end{array}$ & MDD & $0.5 \mathrm{mg} / \mathrm{kg}, \mathrm{IV}$ & Midaz. & Mono. & $\begin{array}{l}\text { SSI at screening, baseline, } 230 \mathrm{~min} \text {, } \\
1,2,3,4,5,6 \text { weeks }\end{array}$ & $\begin{array}{l}\text { Ket. }=40 \\
\text { Midaz. }=40\end{array}$ & $x$ & $\begin{array}{l}\checkmark \text { Masking maintained; \% correct } \\
\text { guesses (Raters, Participants): } \\
\text { Midaz. }(42,55) ; \text { Ket. }(44,55)\end{array}$ \\
\hline Hu et al., 2015 [93] & MDD & $0.5 \mathrm{mg} / \mathrm{kg}, \mathrm{IV}$ & Inact. & Adjunct & $\begin{array}{l}\text { MADRS at screening, baseline, } 1,2 \text {, } \\
4,24,72 \mathrm{hrs}, 7,14,21,28 \text { days }\end{array}$ & $\begin{array}{l}\text { Ket. }=13 \\
\text { Placebo }=14\end{array}$ & $x$ & $x$ \\
\hline $\begin{array}{l}\text { lonescu et al., } 2019 \\
\text { [94] }\end{array}$ & $\begin{array}{l}\text { MDD with } \\
\text { suicidality }\end{array}$ & $0.5 \mathrm{mg} / \mathrm{kg}, \mathrm{IV}$ & Inact. & Mono. & $\begin{array}{l}\text { HDRS at screening, } 1,2 \text { weeks } \\
\text { prior, baseline, } 240 \mathrm{~min}, 3 \mathrm{mth}\end{array}$ & $\begin{array}{l}\text { Ket. }=13 \\
\text { Placebo }=13\end{array}$ & $x$ & $\mathrm{x}$ \\
\hline
\end{tabular}




\begin{tabular}{|c|c|c|c|c|c|c|c|c|}
\hline $\begin{array}{l}\text { lonescu et al., } 2020 \\
\text { [95] }\end{array}$ & $\begin{array}{l}\text { MDD with } \\
\text { suicidality }\end{array}$ & $\begin{array}{l}84 \mathrm{mg} \text { twice } \\
\text { weekly } \\
\text { Intranasal }\end{array}$ & Inact. & Mono. & $\begin{array}{l}\text { MADRS at } 48 \text { hrs prior, baseline, } 4 \text {, } \\
24 \text { hrs, twice weekly for } 6 \text { weeks, } \\
7,8,10,12 \text { wks }\end{array}$ & $\begin{array}{l}\text { Esket. = } 114 \\
\text { Placebo }=113\end{array}$ & $x$ & $\mathrm{x}$ \\
\hline $\begin{array}{l}\text { Jafarinia et al., } 2016 \\
\text { [96] }\end{array}$ & $\begin{array}{l}\text { MDD with } \\
\text { headache }\end{array}$ & $\begin{array}{l}150 \mathrm{mg} / \text { day } \\
\text { thrice weekly, } \\
\text { PO }\end{array}$ & Diclo. & Mono. & $\begin{array}{l}\text { HDRS at screening, baseline, 3, } 6 \\
\text { wks }\end{array}$ & $\begin{array}{l}\text { Ket. }=20 \\
\text { Diclo. }=20\end{array}$ & $\mathrm{x}$ & $\checkmark$ No reporting of results \\
\hline Lai et al., 2014 [97] & MDD & $\begin{array}{l}0.1 / 0.2 / 0.3 / \\
0.4 \mathrm{mg} / \mathrm{kg}, \mathrm{IV}\end{array}$ & Inact. & Mono. & $\begin{array}{l}\text { MADRS at screening, baseline, } 4 \text {, } \\
24,72,168 \mathrm{hrs}\end{array}$ & 4 (cross-over) & $x$ & $\mathrm{x}$ \\
\hline $\begin{array}{l}\text { Lapidus et al., } 2014 \\
\text { [98] }\end{array}$ & MDD & $\begin{array}{l}50 \mathrm{mg}, \\
\text { Intranasal }\end{array}$ & Inact. & Mono. & $\begin{array}{l}\text { MADRS at baseline, } 40,120,240 \\
\min , 24,48,72 \text { hrs, } 7 \text { days }\end{array}$ & 18 (cross-over) & $x$ & $\mathrm{x}$ \\
\hline Li et al., 2016 [99] & MDD & $\begin{array}{l}0.2 / 0.5 \mathrm{mg} / \mathrm{kg}, \\
\text { IV }\end{array}$ & Inact. & Mono. & $\begin{array}{l}\text { HDRS at baseline, } 40,80,120,240 \\
\min \end{array}$ & $\begin{array}{l}\text { Ket. }=32 \\
\text { Placebo }=16\end{array}$ & $x$ & $\mathrm{x}$ \\
\hline Loo et al., 2016 [100] & MDD & $\begin{array}{l}0.1 / 0.2 \text { / } 0.3 / \\
0.4 / 0.5 \mathrm{mg} / \mathrm{kg} \\
\mathrm{IV} / \mathrm{IM} / \mathrm{SC}\end{array}$ & Midaz. & Mono. & $\begin{array}{l}\text { MADRS at screening, baseline, } 4 \\
\text { hours, } 2,4,7 \text {, days }\end{array}$ & 15 (cross-over) & $x$ & $\mathrm{x}$ \\
\hline $\begin{array}{l}\text { Murrough et al., } 2013 \\
\text { [101] }\end{array}$ & MDD & $0.5 \mathrm{mg} / \mathrm{kg}$, IV & Midaz. & Mono. & MADRS at baseline, $1,2,3,7$ days & $\begin{array}{l}\text { Ket. }=47 \\
\text { Midaz. }=25\end{array}$ & $x$ & $\mathrm{x}$ \\
\hline $\begin{array}{l}\text { Murrough et al., } 2015 \\
\text { [102] }\end{array}$ & Suicidality & $0.5 \mathrm{mg} / \mathrm{kg}, \mathrm{IV}$ & Midaz. & Mono. & $\begin{array}{l}\text { BSI at screening, baseline, } 24,48 \text {, } \\
72 \text { hrs, } 7 \text { days }\end{array}$ & $\begin{array}{l}\text { Ket. }=12 \\
\text { Midaz. }=12\end{array}$ & $x$ & $x$ \\
\hline $\begin{array}{l}\text { Nugent et al., } 2019 \\
{[103]}\end{array}$ & MDD & $0.5 \mathrm{mg} / \mathrm{kg}, \mathrm{IV}$ & Inact. & Mono. & $\begin{array}{l}\text { MADRS at screening, baseline, } 40 \text {, } \\
80,120,230 \mathrm{~min}, 1,2,3,7,10,11 \\
\text { days }\end{array}$ & 35 (cross-over) & $x$ & $\mathrm{x}$ \\
\hline $\begin{array}{l}\text { Phillips et al., } 2019 \\
\text { [104] }\end{array}$ & MDD & $0.5 \mathrm{mg} / \mathrm{kg}, \mathrm{IV}$ & Midaz. & Mono. & $\begin{array}{l}\text { MADRS at screening, baseline, 2, } \\
24 \text { hours, } 7 \text { days }\end{array}$ & 39 (cross-over) & $x$ & $x$ \\
\hline $\begin{array}{l}\text { Popova et al., } 2019 \\
{[105]}\end{array}$ & MDD & $\begin{array}{l}56 / 84 \text { mg twice } \\
\text { weekly, } \\
\text { Intranasal }\end{array}$ & Inact. & Adjunct & $\begin{array}{l}\text { MADRS at baseline, } 24 \mathrm{hrs}, 8,15 \text {, } \\
22,28 \text { days }\end{array}$ & $\begin{array}{l}\text { Esket. }=114 \\
\text { Placebo }=109\end{array}$ & $x$ & $x$ \\
\hline $\begin{array}{l}\text { Singh et al., } 2016 \\
{[106]}\end{array}$ & MDD & $\begin{array}{l}0.5 \mathrm{mg} / \mathrm{kg} 2-3 \\
\text { times a week, IV }\end{array}$ & Inact. & Mono. & $\begin{array}{l}\text { MADRS at baseline, after each } \\
\text { dose }\end{array}$ & $\begin{array}{l}\text { Ket. }=35 \\
\text { Placebo }=32\end{array}$ & $x$ & 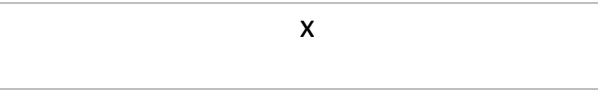 \\
\hline $\begin{array}{l}\text { Sumner et al., } 2020 \\
\text { [107] }\end{array}$ & MDD & $\begin{array}{l}0.25 \mathrm{mg} / \mathrm{kg} \\
\text { bolus, } 0.25 \\
\mathrm{mg} / \mathrm{kg} / \mathrm{hr} \text { for } 45 \\
\mathrm{~min}, \mathrm{IV}\end{array}$ & Remi. & Mono. & $\begin{array}{l}\text { MADRS at screening, baseline, } 3 \text {, } \\
24 \mathrm{hrs}, 1,2,4 \text { wks. }\end{array}$ & 30 (cross-over) & $x$ & $\begin{array}{l}\checkmark \text { Unmasking; \% correct guesses (Raters, } \\
\text { Participants) }=(88,86), \text { confidence }(/ 10) \\
=(8,6)\end{array}$ \\
\hline Xu et al., 2017 [108] & $\begin{array}{l}\text { Postpartum } \\
\text { Depression }\end{array}$ & $0.25 \mathrm{mg} / \mathrm{kg}, \mathrm{IV}$ & Inact. & Mono. & EPDS at 3 days, 6 wks & $\begin{array}{l}\text { Ket. }=162 \\
\text { Placebo }=163\end{array}$ & $x$ & $x$ \\
\hline $\begin{array}{l}\text { Zarate et al., } 2006 \\
\text { [109] }\end{array}$ & MDD & $0.5 \mathrm{mg} / \mathrm{kg}$, IV & Inact. & Mono. & $\begin{array}{l}\text { HDRS at screening, baseline, } 40, \\
80,110,230 \mathrm{~min}, 1,2,3,7 \text { days }\end{array}$ & 18 (cross-over) & $x$ & $x$ \\
\hline
\end{tabular}

[109]

Note. BDI = Beck Depression Inventory, BSS = Beck Suicidality Scale, C-SSRS = Columbia Scale for Suicide Severity Rating, Diclo. = Diclofenac, EPDS = Edinburgh Postnatal Depression Scale, Esket. = esketamine, Expect. $=$ Expectancy, HDRS = Hamilton Depression Rating Scale, IM = Intramuscular, Inact. = Inactive, IV = Intravenous, Ket. = Ketamine, Lan. = Lanicemine, MADRS = Montgomery-Asberg Depression Rating Scale, MDD = Major Depressive Disorder, Midaz. $=$ Midazolam, Mono. $=$ Monotherapy, Remi. $=$ Remifentinal, RoA $=$ Route of Administration, $\mathrm{SC}=$ subcutaneous. 
Table 3: Summary of RCTs of investigating classical psychedelics in mood disorders

\begin{tabular}{|c|c|c|c|c|c|c|c|c|}
\hline Study & Diagnosis & Dosing \& RoA & Placebo & $\begin{array}{l}\text { Mono/ } \\
\text { Adjunct }\end{array}$ & $\begin{array}{c}\text { Primary clinical outcome } \\
\text { measurement }\end{array}$ & $\begin{array}{c}N \\
\text { (per group) }\end{array}$ & $\begin{array}{c}\text { Expect } \\
.\end{array}$ & Masking \\
\hline $\begin{array}{l}\text { Gasser et al., } 2014 \\
{[110]}\end{array}$ & Anxiety & $\begin{array}{l}200 \mu \mathrm{g} L S D, \\
\mathrm{PO}\end{array}$ & $20 \mu \mathrm{g}$ LSD & Adjunct & $\begin{array}{l}\text { STAI at screening, baseline, } 1 \\
\text { week, } 2,12 \mathrm{mths}\end{array}$ & $\begin{array}{l}\text { LSD } 200=8 \\
\text { LSD } 20=3\end{array}$ & $\mathrm{x}$ & $\begin{array}{l}\checkmark \text { Unmasking; \% correct (raters, } \\
\text { participants): } 200 \mu \mathrm{g}(100,100), 20 \mu \mathrm{g}(67, \\
100), \% \text { confidence rated as very certain: } \\
(92,83) .\end{array}$ \\
\hline $\begin{array}{l}\text { Grob et al., } 2011 \\
\text { [111] }\end{array}$ & $\begin{array}{l}\text { Cancer- } \\
\text { related } \\
\text { anxiety }\end{array}$ & $\begin{array}{l}0.2 \mathrm{mg} / \mathrm{kg} \\
\text { psilocybin, } \\
\text { PO }\end{array}$ & Niacin & Mono. & $\begin{array}{l}\text { STAI at baseline, } 1 \text { day, } 2 \text { weeks, } 1 \text {, } \\
2,3,4,5,6 \text { mths }\end{array}$ & 12 (cross-over) & $x$ & $\checkmark$ Unmasking; results not reported \\
\hline $\begin{array}{l}\text { Griffiths et al., } 2016 \\
\text { [112] }\end{array}$ & $\begin{array}{l}\text { Cancer- } \\
\text { related } \\
\text { anxiety / } \\
\text { depression }\end{array}$ & $\begin{array}{l}0.3 / 0.4 \\
\mathrm{mg} / \mathrm{kg} \\
\mathrm{psilocybin}, \\
\mathrm{PO}\end{array}$ & $\begin{array}{l}0.01 \\
\mathrm{mg} / \mathrm{kg} \\
\text { psilocybin }\end{array}$ & Mono. & $\begin{array}{l}\text { HDRS \& HAM-A at screening, } 5 \\
\text { weeks, } 6 \text { mths }\end{array}$ & 51 (cross-over) & $x$ & $\begin{array}{l}\checkmark \text { Rater only; some trial-design masking } \\
\text { maintained }\end{array}$ \\
\hline $\begin{array}{l}\text { Moreno et al., } 2006 \\
\text { [113] }\end{array}$ & OCD & $\begin{array}{l}100 / 200 / \\
300 \mu g / k g \\
\text { Psilocybin, } \\
\text { PO }\end{array}$ & $\begin{array}{l}25 \mu \mathrm{g} / \mathrm{kg} \\
\text { psilocybin }\end{array}$ & Mono. & YBOCS at baseline, 4, 8, $24 \mathrm{hrs}$ & 9 (cross-over) & $x$ & 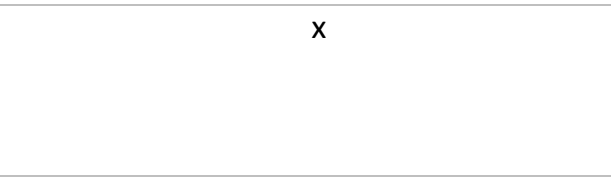 \\
\hline $\begin{array}{l}\text { Palhano-Fontes et } \\
\text { al., } 2019 \text { [114] }\end{array}$ & MDD & $\begin{array}{l}0.35 \mathrm{mg} / \mathrm{kg} \\
\mathrm{N}, \mathrm{N}-\mathrm{DMT} \\
\text { (Ayahuasca) }\end{array}$ & Inactive & Mono. & HDRS at baseline, 7 days & $\begin{array}{l}\text { Aya. }=14 \\
\text { Placebo = } 15\end{array}$ & $\mathrm{x}$ & $\begin{array}{l}\checkmark \text { Participant only; \% correct: Aya }=100, \\
\text { Placebo }=66 .\end{array}$ \\
\hline $\begin{array}{l}\text { Ross et al., } 2016 \\
\text { [115] }\end{array}$ & $\begin{array}{l}\text { Cancer- } \\
\text { related } \\
\text { anxiety }\end{array}$ & $\begin{array}{l}0.3 \mathrm{mg} / \mathrm{kg} \\
\text { psilocybin, } \\
\text { PO }\end{array}$ & Niacin & Adjunct & $\begin{array}{l}\text { HADS at } 2 \text { wks, } 24 \text { hrs prior } \\
\text { (baseline), } 1 \text { day, 2, 6, 7, } 26 \text { wks }\end{array}$ & $\begin{array}{l}29 \text { (cross- } \\
\text { over) }\end{array}$ & $x$ & $\checkmark$ Rater only; \% correct: 97 \\
\hline
\end{tabular}

Note. Adjunct. $=$ Adjunct therapy, Aya. $=$ Ayahuasca, DMT $=$ Dimethyltryptamine, Expect. $=$ Expectancy Measured, HADS $=$ Hospital Anxiety and Depression Scale, HAM-A $=$ Hamilton Anxiety Rating Scale, HDRS $=$ Hamilton Depression Rating Scale, LSD = Lysergic Acid Diethylamide, MDD = Major Depressive Disorder, Mono. = Monotherapy, OCD = Obsessive-Compulsive Disorder, PO = Oral administration, STAI = State-Trait Anxiety Inventory, YBOCS = Yale-Brown Obsessive Compulsive Scale. 
Table 4: Summary of open-label trials of classical psychedelics for mood and addictive disorders

\begin{tabular}{|c|c|c|c|c|c|c|}
\hline Study & Diagnosis & Dosing \& RoA & $\begin{array}{l}\text { Mono/ } \\
\text { Adjunct }\end{array}$ & Primary clinical outcome measurement & $\begin{array}{c}\mathrm{N} \\
\text { (per group) }\end{array}$ & Expect. \\
\hline $\begin{array}{l}\text { Bogenschutz et al., } \\
2015 \text { [116] }\end{array}$ & $\begin{array}{l}\text { Alcohol } \\
\text { dependence }\end{array}$ & $0.3-0.4 \mathrm{mg} / \mathrm{kg}$ psilocybin, $\mathrm{PO}$ & Adjunct & $\begin{array}{l}\text { TLFB for prior to baseline, \% heavy drinking days at baseline, } 1 \text {, } \\
2,3,5,7 \text { ths }\end{array}$ & 10 (cross-over) & $\mathrm{x}$ \\
\hline $\begin{array}{l}\text { Carhart-Harris et al., } \\
2016 \text { [117] }\end{array}$ & MDD & $\begin{array}{l}10 \mathrm{mg} \text { and } 25 \mathrm{mg} \text { psilocybin, } \\
\text { PO }\end{array}$ & Mono. & QIDS at screening, baseline, 1 day, 1, 2, 3, 5 wks, 3 mths & 12 & $\mathrm{x}$ \\
\hline $\begin{array}{l}\text { Davis et al., } 2020 \\
{[118]}\end{array}$ & MDD & $\begin{array}{l}20 \text { and } 30 \mathrm{mg} / \mathrm{kg} \text { psilocybin, } \\
\mathrm{PO}\end{array}$ & Adjunct & HDRS at screening, baseline, 1, 4 wks & $\begin{array}{l}\text { Immediate } \mathrm{tx}=13 \\
\text { Delayed } \mathrm{tx}=11\end{array}$ & $\mathrm{x}$ \\
\hline $\begin{array}{l}\text { Johnson et al., } 2014 \\
\text { [119] }\end{array}$ & $\begin{array}{l}\text { Nicotine } \\
\text { dependence }\end{array}$ & $\begin{array}{l}20 \text { and } 30 \mathrm{mg} / \mathrm{kg} \text { psilocybin, } \\
\text { PO }\end{array}$ & Adjunct & $\begin{array}{l}\text { TLFB, exhaled CO, urinary cotinine level at baseline (intake), } 4 \\
\text { wks prior, } 1,2,3,4 \text {, wks, } 6 \text { mths }\end{array}$ & 15 & $\mathrm{x}$ \\
\hline $\begin{array}{l}\text { Osorio et al., } 2015 \\
{[120]}\end{array}$ & MDD & 1.76 mg/kg DMT (Ayahuasca) & Mono. & $\begin{array}{l}\text { HDRS \& MADRS, at } 2 \text { wks prior, baseline, } 40,80,140,180 \mathrm{~min} \text {, } \\
1,7,14,21 \text { days. }\end{array}$ & 6 & $\mathrm{x}$ \\
\hline $\begin{array}{l}\text { Sanches et al., } 2016 \\
\text { [121] }\end{array}$ & MDD & 1.76 mg/kg DMT (Ayahuasca) & Mono. & $\begin{array}{l}\text { HAM-D \& MADRS at baseline, 40, 80, 140, } 180 \mathrm{~min}, 1,7,14,21 \\
\text { days }\end{array}$ & 17 & $\mathrm{x}$ \\
\hline $\begin{array}{l}\text { Thomas et al., } 2013 \\
{[122]}\end{array}$ & $\begin{array}{l}\text { Problematic } \\
\text { substance } \\
\text { use }\end{array}$ & 50-100 mL Ayahuasca & Adjunct & 4WSUS at screening, 2, 4 weeks, $2,3,4,5 \mathrm{mths}$ & 18 & $\mathrm{x}$ \\
\hline
\end{tabular}

Note. 4WSUS $=4$ Week Substance Use Scale, Adjunct $=$ Adjunct Therapy, CO = Carbon Monoxide, DMT $=$ Dimethyltryptamine, HDRS $=$ Hamilton Depression Rating Scale, MDD $=$ Major Depressive Disorder, MADRS $=$

Montgomery-Asberg Depression Rating Scale, Mono. = Monotherapy, PO = oral administration, QIDS = Quick Inventory of Depressive Symptomology, TLFB $=$ Time-Line Follow Back, tx $=$ treatment 


\section{The Patient Trajectory Through an RCT}

Before considering potential solutions to masking/expectancy/alliance issues in psychedelic RCTs we first review the trajectory of a patient through an RCT and where biases can occur during this process. Identifying these sources of bias is critical before proposing potential remedies. Firstly, it is important to reflect on the fact that the experimental "units" in RCTs do not live in an information vacuum but instead are exposed to a significant amount of knowledge which could potentially shape their response expectancy, their therapeutic alliance, and affect the success of their masking. Specifically, in the context of psychedelics, the popular media has extensively, and generally positively, covered the potential of these drugs to treat mental health conditions. While this positive media coverage is good for the field of psychedelic research after decades of de-facto prohibition [123], it is also likely to amplify response expectancy in patients who enrol in a psychedelic RCT. The pathway of participants through a clinical trial is illustrated in Figure 1. The first-step, trial advertisement, causes an initial sampling bias in terms of which participants from the general eligible population are reached. For trials which operate through clinician referrals, the referring clinician (who may not be involved in the study) may create biases in their selection of patients to refer. The decision of the participant to enquire further around participating in the trial will involve a self-selection bias. The shaping of response expectancy potentially begins at even this earliest stage of an RCT. What information is provided in the RCT advertisement? Do participants know the trial will involve a psychedelic intervention and for what purpose? Our ethics committees have generally encouraged us to use neutral terms in advertising materials such as "new potential antidepressant" to reduce the risk of participants seeking access to controlled substances. Participants who are unwell enough that they seek to take part in an RCT with a relatively extreme, novel intervention may be at their most unwell in their disease time-course. This creates the potential for regression to the mean to occur over the course of a participant's trial enrolment.

Usually, an RCT will involve a triage step involving some pre-screening questions either by email/phone/questionnaire to assess eligibility. This may be handled by a relatively junior member of a research team and may create another potential source of experimenter bias. Provision of potential participants with Participant Information Sheets (PIS) and Consent Forms (CF) provides patients with extensive information regarding the interventions and trial contingencies. In order to meet the requirements of informed consent Ethics Committees generally require that PIS/CFs provide information regarding the benefits and side effects of medicines. In our experience Ethics Committees generally request a description of some of the phenomenological experiences that participants may encounter during the administration of a psychedelic drug. Provision of such information is hard to escape if consent is to be obtained ethically, but it is important to acknowledge that it may reduce masking even in an active-placebo-controlled trial. Further, given that participants will know what drugs they could experience from the PIS, they may easily get more information about the effects of the interventions from the internet to supplement that provided by the research team. In our experience, participants doing their own research regarding drug interventions is common. As we have seen, participant knowledge of experimental design $[38,45]$ such as the number of arms in the trial and knowing the probability (allocation ratio) that they will receive placebo can shape participant expectancy and resultant treatment outcomes. It is important that what participants are told about the trial is clearly reported in the methods 
sections of RCTs. However, the environment and cultural context of pharmaceutical trials is rarely described in RCT reports, and these are likely to have a large impact on both treatment and placebo responses. In a noteworthy example, in the trial protocol of Ballou et al [124] who investigated open-label placebo responses for irritable bowel syndrome, a section was dedicated to "The Culture of the Trial" which contextualised the trial in terms of setting and how participants were interacted with by the research team. For replicability purposes we would suggest this practise should be adopted into psychedelic clinical trial reporting as well as detailing how experimental contingencies are communicated to participants. Providing advertising materials and PIS/CFs as supplementary materials would be useful in this regard.

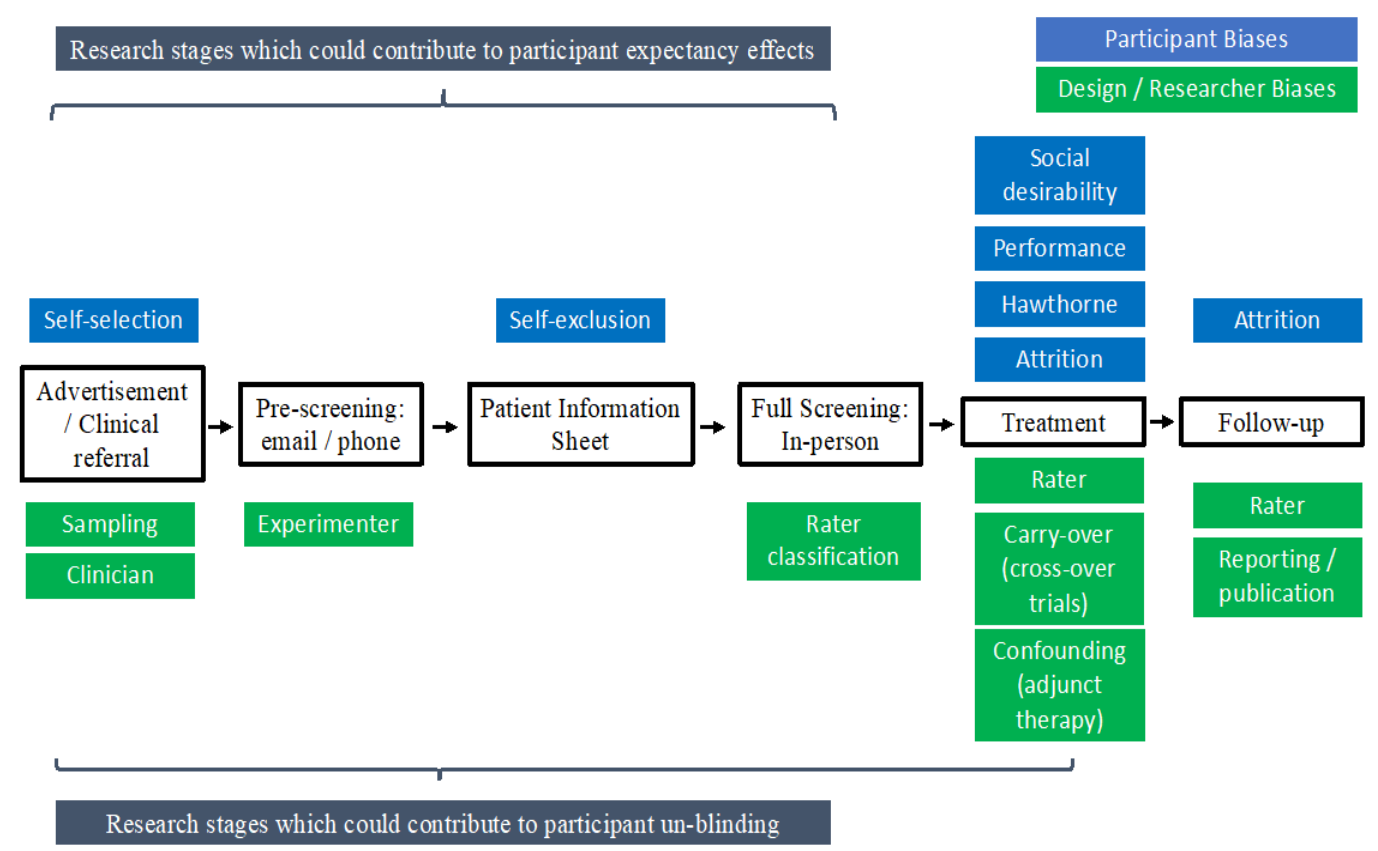

Figure 1: : The trajectory of participants through a psychedelic RCT illustrating the biases that can occur at each stage. Factors that can contribute to expectancy and de-masking are described in text.

The next step in the research process would typically be in-person screening and at this stage patient-therapist alliances can begin to form. From here and during the treatment phase, rater biases as well participant biases including Hawthorne effects and social desirability can emerge. Post-randomisation attrition bias (dealt with using Intention to Treat analyses) and carryover effects in crossover trials can also be present. Finally, we note that throughout the entire research process researcher biases can easily emerge. The scientists engaged in psychedelic research are self-selected and have their own personal motivations to conduct research in this area. Most psychedelic RCTs (Section Reporting of Masking and Expectancy in Psychedelic RCTs) reported to date are relatively small Phase 2 trials conducted in academic settings whereas large-scale Phase 3 pharmaceutical trials are generally conducted at Contract Research Organisations removed in operational terms from the trial sponsors. Both types of trials have their own potential sources of biases based on the motivations (academic vs commercial) to conduct the trial. One excellent remedy for these biases is to publish registered reports with peer review including statistical analysis plans prior to the commencement of the psychedelic RCT - not simply clinical trial registrations which often provide minimal information. Despite more than 150 journals [125] now offering 
registered report formats we are not aware that this practise has yet been adopted for psychedelic RCTs. Given the various biases that might occur in psychedelic RCTs discussed in this section we now consider potential trial designs that might be used to address these concerns.

\section{Trial Designs for Psychedelic RCTs}

While $A T E=E\left(Y_{t}\right)-E\left(Y_{c}\right)$ as per Equation 2, this estimator is only true when participants are unable to guess their allocation. As has been described, ATE is potentially heavily influenced by participants' belief about their allocation. If we add a 3rd variable to our data $B$ which indicates the belief that participants have about what treatment they are receiving then for each unit in an RCT we have $\left(S, Y_{s}, B_{s}\right)$ (see Section Causal Inference and the Randomised Controlled Trial). $B$ might be a categorical or ordinal variable where $1=$ believes allocated to treatment, $0=$ belief uncertain and $-1=$ believes allocated to placebo. In order to remove bias due to belief allocation we propose that the treatment effect should be conditioned on $\mathrm{B}$ :

$$
\boldsymbol{A T E}(\boldsymbol{b})=E\left[Y_{t}-\mathbf{Y}_{\mathbf{c}} \mid \mathbf{B}_{\mathrm{t}}=\mathbf{b} \cap B_{c}=b\right](14)
$$

In typical RCTs, experimentalists use masking to generate uncertainty in belief around allocation and in ideal circumstances $B_{t}=B_{c}=0$, with high probability, so that ATE and $\mathrm{ATE}(0)$ will be approximately equal. For the treatment group in a psychedelic RCT, given the obvious psychological effects, most participants administered the psychedelic will believe strongly that they are in the treatment group $\left(B_{t}=1\right)$. The key experimental challenge is then to create contingencies so that participants in the control group believe they are in the treatment group $\left(B_{c}=1\right)$. That is, rather than trying to accomplish a design which creates relatively high uncertainty in both groups, trying to achieve high (but incorrect) intuitions regarding certainty in the control group, and estimating ATE(1), might be more appropriate for psychedelic RCTs ${ }^{2}$. It is not possible to observe both $\boldsymbol{B}_{\boldsymbol{c}}$ and $\mathbf{B}_{\mathbf{t}}$, but if $\mathbf{B}_{\mathbf{t}}=1$ for treated participants and $\boldsymbol{B}_{\boldsymbol{c}}=1$ for control participants, it is reasonable that $\mathrm{B}_{\mathrm{t}}=\mathrm{B}_{\mathrm{c}}=1$.

It is possible to weaken the condition in Equation 14, for example, to a condition that $B_{t}-B_{c}$ is independent of $S$, allowing uncertainty about blinding as long as it is uninformative.

An important tool for experimenters in RCTs to help achieve this is to use active placebos. Table 2 shows that midazolam and remifentanil have been used as active placebos for intravenous ketamine and diclofenac for oral ketamine, with midazolam being the most commonly used active comparator. Due to limited reporting, it is unclear how effective these active placebos are at maintaining masking but there does seem to be partial success. Interestingly a meta-analysis [127] of RCTs of ketamine for MDD compared studies which used saline as a placebo with studies that used midazolam as a placebo and showed dramatic changes in observed effect size. The effect size for saline studies was $d=1.8$, and for those using midazolam $d=0.7$. This effect was primarily driven by an increased placebo response to midazolam. It remains to be seen what the effect size would be under perfectly maintained masking as masking has only been assessed in a few studies and appears to be only partly maintained (Table 2). The meta-analysis in [127] is completely consistent with the notion that

\footnotetext{
${ }^{2}$ It is inappropriate to apply regression approaches such as ANCOVA (or similar) to regress out blinding /confidence status from treatment outcome when there are between-group differences in the covariate [126]. As such, some degree of balance must be achieved through experimental design.
} 
ATE in trials of ketamine for MDD is overestimated. It could be argued that midazolam is not a perfect active comparator from a theoretical perspective as it is a known anxiolytic, and anxiety is one of the sub-scales in commonly used outcome measures such as MADRS and HAM-D. That said, midazolam's anxiolytic effect may be relatively short compared to the potential antidepressant effects of ketamine.

For serotonergic psychedelics several active placebos have been used although none appear to have been successful in maintaining masking. Table 2 shows one choice of active placebo that has been used is niacin. The use of niacin has historical roots from Pahnke's "Marsh-Chapel" experiment from 1962 where it was used as an active comparator for psilocybin. However, although niacin does create some warm flushing due to vasodilation, its use as an active placebo did not maintain masking in any of Pahnke's participants [128]. Amphetamines have also previously been used as active comparators for LSD in the first wave of psychedelic research [12]. Another potential approach is to use low doses of drug being studied $[110,112,113]$.

By themselves, active placebos may be insufficient to successfully maintain masking. We argue that active placebos may need to be used in combination with alternative trial designs alongside some mild deception/vagueness in the information about trial contingencies provided to participants. This would require careful discussion with Ethics Committees but may be permittable given careful scientific justification and debriefing strategies. In some scenarios in order to meet equipoise principles [129], patients who do not receive active treatment can be offered entry into an open-label extension arm. We next consider some clinical trial designs that have, and could, be used in psychedelic RCTs and comment on their appropriateness in this context. Designs are displayed graphically in Figure 3.

\subsection{Placebo Lead-in Periods - Not recommended}

A trial design that has been used in trials of standard antidepressants is the placebo lead-in design (Figure 2a) which can be either single- or double-masked. In this design, all participants are initially treated with placebo. Placebo responders are removed from the trial (or moved into an open-label extension), while non-responders are randomised into the main phase of the RCT. In studies of standard antidepressants the use of participant-masked lead-in periods does not appear to modify the number of placebo responders [130] or size of the placebo response [131] although double-masked lead-ins with variable lead-in periods may be more effective [132]. The placebo lead-in trial is built around the theoretical position that there are individuals who have a trait characteristic of being placebo responders, although the evidence for is relatively weak [133]. In the context of psychedelic RCTs and the theoretical framework we propose, placebo lead-in periods might be entirely counter-productive. Placebo responders are the participants most likely to believe they have been given the active treatment and by Equation 14 are the very ones that we would like to retain for the control group $\left(B_{c}=1\right)$. Conversely, placebo non-responders may have deduced that the placebo is in fact placebo $\left(B_{c}=-1\right)$. Hence, this would end up maximising the difference between $B_{c}$ and $B_{t}$ which is the opposite of the desired belief situation. 


\subsection{Sequential Parallel Comparison Design (SPCD) - Not recommended}

The SPCD RCT [134] is somewhat similar to using a placebo lead-in period. The SPCD RCT (Figure $2 \mathrm{~b}$ ) consists of two intervention phases. Participants are allocated to either drug-drug, placebo-drug or placebo-placebo groups. Responders are removed after Phase 1, meaning that approximately half of placebo non-responders will then be switched to the active condition. Similar to the placebo lead-in period this is thought to reduce the placebo response but as argued for the placebo lead-in trial, the same issue with unequal belief attribution across groups arises. Moreover, psychedelic RCTs are mostly "one-shot" interventions rather than long medication trials which the SPCD is designed for. There may, however, be a role for the SPCD RCT in investigating the therapeutic effects of psychedelic microdosing.

\subsection{Crossover trials - Not recommended}

In our view, crossover trials such as the $2 \times 2$ crossover (Figure $2 c$ ) are not ideal for psychedelic RCTs where treatment response is the primary outcome being investigated. Not only is there potential for carryover in the primary outcome measure, just as problematically there is the potential that the beliefs of participants around which intervention they have received could change as they move through trial periods and even within the first washout phase as intuitions around efficacy develop. Moreover, such a change could depend on which sequence arm they are allocated to. For brevity, we do not provide a full exposition of this which would require a lengthy introduction to the statistical approach used for crossover design (see [135]). However, the complex interactions between carryover, belief allocation, efficacy, arms and sequence are likely to counteract any statistical efficiencies derived from the repeated-measures nature of crossover trials.

\subsection{Delayed Treatment Design - Not recommended}

In the delayed treatment design [30] (Figure 2d) all participants are told they will receive either drug or placebo, however the timing of the active treatment is not disclosed. Some participants receive active treatment immediately while the rest receive placebo. After a delay the active intervention is introduced into the placebo group. For this design to work in a psychedelic RCT an active comparator would need to be used to achieve some kind of belief allocation in the delayed treatment group. However, it would be very difficult in practice to balance the two groups in terms of number of interventions and visits and with an active comparator the design turns into an incomplete crossover design. A delayed treatmentdesign (with no placebo intervention) has previously been used in an RCT of psilocybin for depression[118]. While this design does allow excellent characterisation of pre-treatment symptom stability in the delayed treatment group it does not address masking issues.

\subsection{Parallel Groups Design with Active Comparator}

A standard parallel groups design with an active comparator (Figure 2e) may still be appropriate provided that the active comparator has convincing enough psychedelic properties that a reasonable patient given placebo would believe they had been allocated to 
the treatment. For example, take a trial where the treatment is ketamine and midazolam is the active placebo. Pre-testing might indicate that all participants in the ketamine group might correctly guess their treatment arm, while half of those given midazolam may believe they had been administered ketamine. In the RCT, participants could be allocated in a 1:2 ratio favouring placebo, although it is not necessary to state the allocation ratio to participants; indeed there may be advantages to mild deception for this factor. As per Section Assessment of Masking Success in Clinical Trials, soon after the intervention, but prior to outcome assessment, belief about the allocation intervention can be measured (B). Only those participants in the control group who believe they are in the active group $\left(B_{c}=1\right)$ will be included in the statistical comparison to the active group in order to assess ATE (Equation 14). As noted above, sophisticated approaches are possible where there is a greater uncertainty in $B$ as long as the uncertainty is not informative about actual treatment. One potential issue with this design is because the stratification on B is performed postrandomisation, one can no longer assume that pre-trial covariates are balanced.

\subsection{Dose-Response Parallel Groups Design}

In some implementations this can be conceptually similar to the parallel groups design described above where the active comparator is a low dose of the treatment. For example, the trial by Gasser et al [110] investigating LSD for the treatment of anxiety used $200 \mu \mathrm{g}$ as the active dose and $20 \mu \mathrm{g}$ an active comparator - although in that trial masking was not maintained. The dose-response approach (Figure 2f) depends on the validity of the assumption that the low dose is not in fact therapeutic. Given the increasing interest in microdosing of psychedelics for the treatment of mental health this may be of concern. As a cautionary tale consider the open-label trial of psilocybin for depression conducted by Carhart-Harris et al [136]. After the first "small" $10 \mathrm{mg}$ dose of psilocybin HAM-D scores dropped from 21.4 to 10.7 and after the full dose $(25 \mathrm{mg})$ these dropped to 7.4 . That is, $76 \%$ of the therapeutic effect on the HAM-D was elicited by the small dose. In the case where a dose-response RCT was perfectly masked then ATE might be underestimated if the low dose is eliciting a treatment effect. Nevertheless, given that we have argued all estimates of ATE in psychedelic trials to date are overestimated, an underestimated yet statistically significant ATE would be convincing evidence.

One potential feature that we have not seen implemented for the dose response design is that it may be possible by deception or omission to not inform participants that the trial in fact contains two or more dose level groups. Obviously, this would require extra discussion with Ethics Committees to implement. It is noteworthy that the parallel group design with a different drug comparator would generally require, for ethical reasons, that participants be informed of the different drugs that they may receive. However, not informing a participant that they may in fact receive a lower dose may be permitted. An open-label extension may ameliorate issues related to clinical equipoise. There would need to be great care in the debrief given to participants - particularly making sure that future participants are not informed of the hidden trial contingencies - to avoid violating the SUTVA assumption. Probing participants' "belief" around allocation would also require care, as participants would not be aware that there were different arms in the trial.

\subsection{Pre-Treatment Parallel Groups Design}


Similar to the parallel groups design, but here active treatment is preceded by a pharmacological antagonist (Figure $2 \mathrm{~g}$ ). For example, the opioid receptor antagonist naltrexone has been found to block the antidepressant effects of ketamine [137], while lamotrogine blocks some of ketamine's psychedelic properties [138, 139]. For classical psychedelics, the $5 \mathrm{HT}_{2 \mathrm{~A}}$ receptor antagonist ketanserin has been shown to block the psychological effects of both LSD [140] and psilocybin in a dose dependent manner - with 20 $\mathrm{mg}$ ketanserin leading to partial blockade and $40 \mathrm{mg}$ near complete blockade [141]. In a recent dose-response crossover design study of LSD in healthy volunteers by Holze et al [142] participants were given LSD doses of $25 \mu \mathrm{g}, 50 \mu \mathrm{g}, 100 \mu \mathrm{g}$ or $200 \mu \mathrm{g}$ or $200 \mu \mathrm{g}$ with ketanserin (40 mg). Participants were asked to retrospectively identify these conditions - after each session and at the end of the study. Accuracy was generally high indicating de-masking although notably the +ketanserin condition was most commonly mistaken for 50/25 $\mu \mathrm{g}$ of LSD.

For a potential therapeutic RCT using pre-treatment, a design similar to the doseresponse design could be used, with dose modification of the pre-treatment rather than the active drug. In that way all participants would receive the full dose but not all would receive its full effect. We note that while participants may need to be informed that a pre-treatment is being used it may be ethically permittable to not disclose its experimental purpose. For example, ketanserin could be accurately described as "controlling blood pressure" during the intervention while concealing its real purpose; to limit the psychedelic experience. One advantage of the pre-treatment design is that it may allow for the examination of the impact of specific receptors on ATE generation. For example, in the case of LSD and psilocybin, ketanserin allows specific neurobiological inferences around activity at the $5 \mathrm{HT}_{2 \mathrm{~A}}$ receptor.

\subsection{Balanced Placebo Factorial Design}

The balanced placebo design $[29,30]$ is a $2 \times 2$ factorial design (Figure $2 \mathrm{~h}$ ) with one factor of intervention (given drug I given placebo) and one factor of instructions - what drug they are told they will receive (told drug | told placebo). The four conditions are therefore a) the participant is given the treatment and is told they are receiving the treatment, $b$ ) the participant is given the treatment and is told they are receiving placebo, $c$ ) the participant is given the placebo and is told they are receiving placebo and d) the participant is given the placebo and is told they are receiving the treatment. Conditions b) and d) involve explicit use of deception. The balanced placebo design was devised to examine interactions between drug effects and non-specific effects such as expectancy. In the context of psychedelic RCTs, if coupled with an active comparator, the use of deceptive (or ambiguous) instructions may help to manipulate the participants' beliefs around which intervention they have received, when asked after the intervention and before outcome assessment. In particular, for group $b$ ) it may allow $\hat{B}_{t}<1$ which might be helpful if the active comparator alone is insufficient to create $\hat{B}_{c}=1$. In analysis, participants could be selected to allow $B_{t}=B_{c}$. The design itself is somewhat inefficient in the context of psychedelic RCTs as group $c$ ) is not particularly useful. That said, it is not necessary that a 1:1:1:1 allocation ratio be used. With regards to ethical issues around the use of deception, authorised deception can potentially be used where participants are informed that incomplete information is being provided [29, 30]. Open-label extensions could also lessen the ethical issues. One downside with factorial designs is that the extra conditions mean considerable numbers of patients would need to be recruited. 
Adequately powering such a study may be beyond the resources available to a single-study site.

\subsection{Enrichment Factorial Design}

A somewhat similar design to the balanced placebo design is the $2 \times 2$ enrichment design (Figure 2i) proposed by Carhart-Harris et al [35] (see also [30]). In this factorial design, one factor is the intervention (drug | placebo), and one factor is environmental enrichment (enriched | unenriched). This is an excellent design in terms of looking at which environmental factors might be used to enhance the effectiveness of psychedelic therapy. Taken alone though, issues of masking still remain. If combined with an active comparator then it may be possible to achieve $B_{t}$. $=B_{c}$. and could be a more elaborate version of either the parallel groups with active comparator design, dose response design or pre-treatment parallel groups design as described. Similar to the balanced placebo design, adequately powering such a study may be challenging.

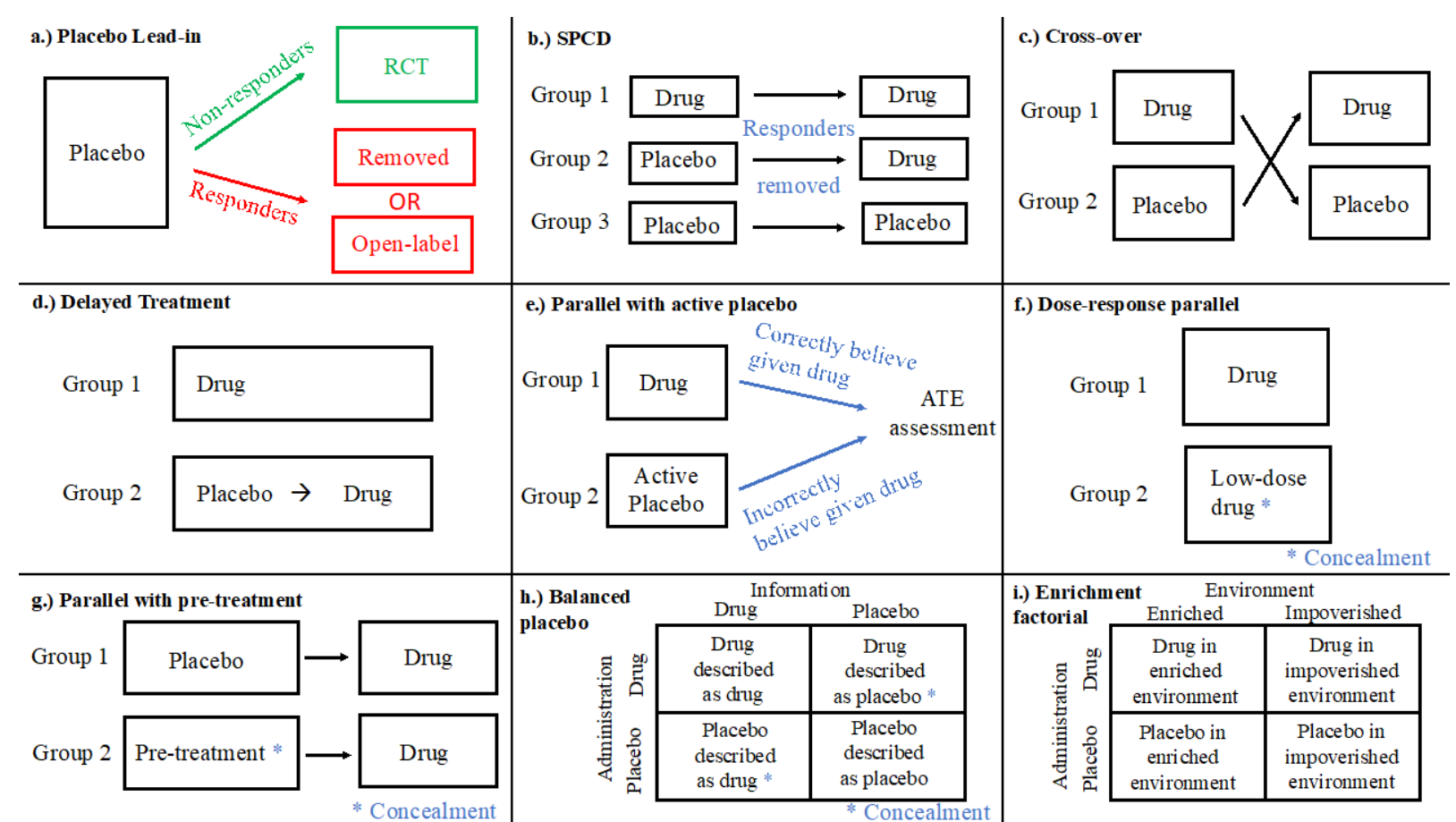

Figure 2: Potential Trial designs for psychedelic RCTs as described in text. Designs a-d are not recommended.

\section{Statistical Models and Assumptions}

In this section we consider a sequence of progressively more realistic scenarios and the analyses they imply. It will typically not be possible to estimate causal parameters precisely by relying simply on randomisation, but it is reasonable to expect the combination of randomisation and modelling to lead to reduced bias. 
1. If Equation 14 is satisfied for all participants, meaning that blinding is achieved by experimental design, the simple difference in means estimates an average treatment effect and the standard analysis is valid. When B is measured it will still often be of interest to estimate $\operatorname{ATE}(b)$ and examine the extent to which the treatment effect varies according to which treatment the participants believe they have received. Simplifying to a linear model (for exposition), the observed data can be modelled as:

$$
E[Y \mid S, B]=\delta S+\alpha B+\beta B S
$$

and $\operatorname{ATE}(\mathrm{b})$ estimated as $\delta+2 \beta b$.

2. If Equation 14 is satisfied only for a subset, confounding has been induced by conditioning on the observed value of $B$, which is affected by randomisation. Specifically, typical participants will have $B_{t}=1$, and so $B=1$ in the treatment group, but only the more easily influenced participants will have $B_{c}=1$ and so $B=1$ in the control group. We have only the same statistical model to estimate $A T E(b)$, but a causal interpretation is no longer guaranteed simply by randomisation. It is still possible to average ATE(b) over different values of $b$, but weights for averaging must be chosen based on the distribution of $B$ in the treatment or control group or a combination of the two.

3. To the extent that $\mathrm{B}_{\mathrm{c}}$ for an individual is dependent on factors such as expectancy and suggestibility, it will be possible to replace the conditioning on the post-randomisation $B$ with conditioning on pre-randomisation measurement of these factors (E). A linear estimation model would then be:

$$
E[Y \mid S, E]=\delta S+\alpha E+\beta S E
$$

This model does not include post-randomisation covariates. Measurements of B can still be used to check that $B$ is (approximately) independent of treatment conditional on $E$.

4. When expectancy and suggestibility capture only part of the variation in blinding, a model conditioning on both $B$ and $E$ may be needed:

$$
E[Y \mid S, E, B]=\delta S+\alpha_{e} E+\alpha_{b} B+\beta_{e} S E+\beta_{b} S B
$$

This model conditions on post-randomisation $B$, which will typically induce bias, but the association between $\mathrm{Y}$ and $\mathrm{B}$ will be weaker in this model than without $\mathrm{E}$.

5. So far we have not considered measurement error in B and E. As is familiar in mediation analyses, if $\mathrm{B}$ or $\mathrm{E}$ are measured with error, conditioning on them will only partially block a causal path even if it would be blocked completely by measuring them without error. Where feasible, it would be of use to consider measurement error models based on separate studies of test-retest accuracy[143]. 


\section{Conclusions}

In summary, this paper has attempted to outline the fundamental logic for how RCTs are used to establish causal relationships between treatments and outcomes using the formalism of the Rubin causal model and how standard RCT designs may be inappropriate in trials of psychedelic treatments. During these trials, a number of factors potentially allow participants to experience strong expectancy regarding intervention effects. When these strong expectancy effects are coupled with de-masking the potential for treatment effects (ATE) to be over-estimated in psychedelic RCTs is substantially heightened. To counter this problem, we have suggested several approaches that could improve the evidence for causation. In particular, psychedelic RCTs should include measurement of expectancy using tools such as the CEQ or SETS, assessment of masking following psychedelic interventions using standard questions and indexes and, where relevant, patient-therapist alliance should be measured throughout the trial. Out of the nine considered RCT designs, five showed promise to be used (some with modification) in psychedelic trials. Special care should be given to the instructions and information provided to participants - which can shape their expectancy and perception of masking during the trial. We suggest augmenting current reporting standards; including factors such as the culture/context of the trial along with publishing PIS/advertising materials and any other instructions that are provided to participants. Finally, more psychedelic RCTs should employ full pre-publication of trial protocols.

This paper has limited its scope to the role that RCTs might play in establishing a causal role for psychedelics in treating psychiatric diseases. However, it is important to acknowledge that other forms of evidence are used in medicine to establish causation. These could be considered in future work; for example the application of the Bradford-Hill criteria [23] or the potential for surrogate biomarkers (such as blood or neuroimaging biomarkers) to be used in order to strengthen evidence for causality. Indeed, one shortcoming of relying solely on clinical trial and ATE estimation from a scientific perspective is the lack of any consideration for mechanistic credibility. The philosophers Cartwright and Hardie [144] write "We suppose that causes do not produce their effects by accident, at least not if you are to be able to make reliable predictions about what will happen if you intervene. Rather, if a cause produces an effect, it does so because there is a reliable, systematic connection between the two, a connection that is described in a causal principle" (Ch2, pg 8). Psychedelic science is making rapid advances in understanding the mechanistic basis by which psychedelics exert effects at both molecular- and systems-levels. In the future integrating mechanistic information into purely statistical considerations of treatment effects may help to establish a firm scientific foundation for if, and how, psychedelics exert therapeutic action. 


\section{References}

1. Peace, K.E. and D.-G. Chen, Clinical Trial Methodology. CRC Biostatistics Series. 2010, Boca Raton, Fl: Chapman \& Hall.

2. Chow, S.-C. and J.P. Liu, Design and Analysis of Clinical Trials: Concepts and Methodologies. 3rd Edition ed. 2014, Hoboken, New Jersey: John Wiley \& Sons,.

3. Rubin, D.B., Estimating causal effects of treatments in randomized and nonrandomized studies. Journal of Educational Psychology, 1974. 66(5): p. 688-701.

4. Holland, P.W., Statistics and Causal Inference. Journal of the American Statistical Association, 1986. 81(396): p. 945-960.

5. Deaton, A. and N. Cartwright, Understanding and misunderstanding randomized controlled trials. Soc Sci Med, 2018. 210: p. 2-21.

6. Rothwell, P.M., External validity of randomised controlled trials: "to whom do the results of this trial apply?". Lancet, 2005. 365(9453): p. 82-93.

7. Bothwell, L.E. and S.H. Podolsky, The Emergence of the Randomized, Controlled Trial. New England Journal of Medicine, 2016. 375(6): p. 501-504.

8. Podolsky, S.H., D.S. Jones, and T.J. Kaptchuk, Chapter 3 - From Trials to Trials: Blinding, Medicine, and Honest Adjudication, in Blinding as a Solution to Bias, A.S. Kesselheim and C.T. Robertson, Editors. 2016, Academic Press: San Diego. p. 45-58.

9. Junod, S.W. FDA and Clinical Drug Trials: A Short History. Available from: https://www.fda.gov/media/110437/download.

10. Hoffmann, A., LSD: My problem child. 2013: Oxford University Press.

11. Grinspoon, L., Psychedelic drugs reconsidered / Lester Grinspoon \& James B. Bakalar, ed. J.B. Bakalar. 1979, New York: Basic Books.

12. Krebs, T.S. and P.O. Johansen, Lysergic acid diethylamide (LSD) for alcoholism: metaanalysis of randomized controlled trials. J Psychopharmacol, 2012. 26(7): p. 9941002.

13. Beecher, H.K., The powerful placebo. J Am Med Assoc, 1955. 159(17): p. 1602-6.

14. Kaptchuk, T.J., Powerful placebo: the dark side of the randomised controlled trial. The Lancet, 1998. 351(9117): p. 1722-1725.

15. Rutherford, B.R. and S.P. Roose, $A$ model of placebo response in antidepressant clinical trials. The American journal of psychiatry, 2013. 170(7): p. 723-733.

16. Hróbjartsson, A. and P.C. Gøtzsche, Is the Placebo Powerless? New England Journal of Medicine, 2001. 344(21): p. 1594-1602.

17. Miller, F.G. and D.L. Rosenstein, The nature and power of the placebo effect. Journal of Clinical Epidemiology, 2006. 59(4): p. 331-335.

18. Kirsch, I. and A. Scoboria, Apples, oranges, and placebos: heterogeneity in a metaanalysis of placebo effects. Adv Mind Body Med, 2001. 17(4): p. 307-9; discussion 312-8.

19. Ader, R., Much ado about nothing. Adv Mind Body Med, 2001. 17(4): p. 293-5; discussion 312-8.

20. Greene, P.J., et al., The powerful placebo: doubting the doubters. Adv Mind Body Med, 2001. 17(4): p. 298-307; discussion 312-8.

21. Benedetti, F., Placebo effects: from the neurobiological paradigm to translational implications. Neuron, 2014. 84(3): p. 623-37.

22. Turner, J.A., et al., The Importance of Placebo Effects in Pain Treatment and Research. JAMA, 1994. 271(20): p. 1609-1614. 
23. Glasziou, P., et al., When are randomised trials unnecessary? Picking signal from noise. BMJ, 2007. 334(7589): p. 349.

24. Jamshidian, F., A.E. Hubbard, and N.P. Jewell, Accounting for perception, placebo and unmasking effects in estimating treatment effects in randomised clinical trials. Stat Methods Med Res, 2014. 23(3): p. 293-307.

25. Kaptchuk, T.J., The double-blind, randomized, placebo-controlled trial: gold standard or golden calf? J Clin Epidemiol, 2001. 54(6): p. 541-9.

26. Dahan, R., et al., Does informed consent influence therapeutic outcome? A clinical trial of the hypnotic activity of placebo in patients admitted to hospital. British medical journal (Clinical research ed.), 1986. 293(6543): p. 363-364.

27. Bergmann, J.F., et al., A randomised clinical trial of the effect of informed consent on the analgesic activity of placebo and naproxen in cancer pain. Clin Trials Metaanal, 1994. 29(1): p. 41-7.

28. Miller, F.G. and D.L. Rosenstein, The nature and power of the placebo effect. J Clin Epidemiol, 2006. 59(4): p. 331-5.

29. Kirsch, I., Are drug and placebo effects in depression additive? Biological Psychiatry, 2000. 47(8): p. 733-735.

30. Kube, T. and W. Rief, Are placebo and drug-specific effects additive? Questioning basic assumptions of double-blinded randomized clinical trials and presenting novel study designs. Drug Discov Today, 2017. 22(4): p. 729-735.

31. Hartogsohn, I., Set and setting, psychedelics and the placebo response: An extrapharmacological perspective on psychopharmacology. J Psychopharmacol, 2016. 30(12): p. 1259-1267.

32. Strassman, R. The Political Correction of Psychedelics. Part 3. Psychedelics as SuperPlacebos. 2017; Available from: https://www.rickstrassman.com/the-politicalcorrection-of-psychedelics-part-3-psychedelics-as-super-placebos.

33. Kaptchuk, T.J., et al., Components of placebo effect: randomised controlled trial in patients with irritable bowel syndrome. BMJ, 2008. 336(7651): p. 999-1003.

34. Gukasyan, N. and S. Nayak, Psychedelics, placebo effects, and set and setting: insights from common factors theory of psychotherapy. Transcultural Psychiatry: Cultural Contexts and Ethical Issues in the Therapeutic Use of Psychedelics, 2020. in press.

35. Carhart-Harris, R.L., et al., Psychedelics and the essential importance of context. J Psychopharmacol, 2018. 32(7): p. 725-731.

36. Kirsch, I., Response Expectancy and the Placebo Effect. Int Rev Neurobiol, 2018. 138: p. 81-93.

37. Zilcha-Mano, S., et al., Not Just Nonspecific Factors: The Roles of Alliance and Expectancy in Treatment, and Their Neurobiological Underpinnings. Frontiers in behavioral neuroscience, 2019. 12: p. 293-293.

38. Rutherford, B.R., J.R. Sneed, and S.P. Roose, Does study design influence outcome?. The effects of placebo control and treatment duration in antidepressant trials. Psychotherapy and psychosomatics, 2009. 78(3): p. 172-181.

39. Papakostas, G.I. and M. Fava, Does the probability of receiving placebo influence clinical trial outcome? A meta-regression of double-blind, randomized clinical trials in MDD. Eur Neuropsychopharmacol, 2009. 19(1): p. 34-40. 
40. Constantino, M.J., et al., A meta-analysis of the association between patients' early treatment outcome expectation and their posttreatment outcomes. Psychotherapy (Chic), 2018. 55(4): p. 473-485.

41. Kaertner, L.S., et al., Positive expectations predict improved mental-health outcomes linked to psychedelic microdosing. Scientific Reports, 2021. 11(1): p. 1941.

42. Borkovec, T.D. and S.D. Nau, Credibility of analogue therapy rationales. Journal of Behavior Therapy and Experimental Psychiatry, 1972. 3(4): p. 257-260.

43. Devilly, G.J. and T.D. Borkovec, Psychometric properties of the credibility/expectancy questionnaire. Journal of Behavior Therapy and Experimental Psychiatry, 2000. 31(2): p. 73-86.

44. Rutherford, B.R., et al., A randomized, prospective pilot study of patient expectancy and antidepressant outcome. Psychol Med, 2013. 43(5): p. 975-82.

45. Rutherford, B.R., et al., Patient Expectancy as a Mediator of Placebo Effects in Antidepressant Clinical Trials. The American journal of psychiatry, 2017. 174(2): p. 135-142.

46. Younger, J., et al., Development of the Stanford Expectations of Treatment Scale (SETS): A tool for measuring patient outcome expectancy in clinical trials. Clinical Trials, 2012. 9(6): p. 767-776.

47. Dore, J., et al., Ketamine Assisted Psychotherapy (KAP): Patient Demographics, Clinical Data and Outcomes in Three Large Practices Administering Ketamine with Psychotherapy. Journal of Psychoactive Drugs, 2019. 51(2): p. 189-198.

48. Krupitsky, E.M. and A.Y. Grinenko, Ketamine psychedelic therapy (KPT): a review of the results of ten years of research. J Psychoactive Drugs, 1997. 29(2): p. 165-83.

49. Flückiger, C., et al., The alliance in adult psychotherapy: A meta-analytic synthesis. Psychotherapy (Chic), 2018. 55(4): p. 316-340.

50. Posternak, M.A. and M. Zimmerman, Therapeutic effect of follow-up assessments on antidepressant and placebo response rates in antidepressant efficacy trials: metaanalysis. Br J Psychiatry, 2007. 190: p. 287-92.

51. Rutherford, B.R., et al., Clinic visits in late-life depression trials: effects on signal detection and therapeutic outcome. The American journal of geriatric psychiatry : official journal of the American Association for Geriatric Psychiatry, 2014. 22(12): p. 1452-1461.

52. Furukawa, T.A., et al., Placebo response rates in antidepressant trials: a systematic review of published and unpublished double-blind randomised controlled studies. Lancet Psychiatry, 2016. 3(11): p. 1059-1066.

53. ICH Harmonised Tripartite Guideline. Statistical principles for clinical trials. International Conference on Harmonisation E9 Expert Working Group. Stat Med, 1999. 18(15): p. 1905-42.

54. Sumner, R.L., et al., Ketamine Enhances Visual Sensory Evoked Potential Long-term Potentiation in Patients With Major Depressive Disorder. Biol Psychiatry Cogn Neurosci Neuroimaging, 2020. 5(1): p. 45-55.

55. Hróbjartsson, A., et al., Bias due to lack of patient blinding in clinical trials. A systematic review of trials randomizing patients to blind and nonblind sub-studies. International journal of epidemiology, 2014. 43(4): p. 1272-1283.

56. Savovic, J., et al., Influence of reported study design characteristics on intervention effect estimates from randomised controlled trials: combined analysis of metaepidemiological studies. Health Technol Assess, 2012. 16(35): p. 1-82. 
57. Nüesch, E., et al., The importance of allocation concealment and patient blinding in osteoarthritis trials: A meta-epidemiologic study. Arthritis Care \& Research, 2009. 61(12): p. 1633-1641.

58. Higgins, J.P.T., et al., Revised Cochrane risk-of-bias tool for randomized trials (RoB 2). 2019.

59. Caddy, C., et al., Ketamine and other glutamate receptor modulators for depression in adults. Cochrane Database Syst Rev, 2015(9): p. Cd011612.

60. Moncrieff, J., S. Wessely, and R. Hardy, Active placebos versus antidepressants for depression. Cochrane Database of Systematic Reviews, 2004(1).

61. Ney, P.G., C. Collins, and C. Spensor, Double blind: double talk or are there ways to do better research. Med Hypotheses, 1986. 21(2): p. 119-26.

62. Howick, J., The Philosophy of Evidence-Based Medicine. 2011: BMJ Books. WlleyBlackwell. 63-79.

63. Murrough, J.W., et al., Antidepressant efficacy of ketamine in treatment-resistant major depression: a two-site randomized controlled trial. Am J Psychiatry, 2013. 170(10): p. 1134-42.

64. Sumner, R., et al., Ketamine enhances visual sensory evoked potential LTP in patients with major depressive disorder. Biological Psychiatry: Cognitive Neuroscience and Neuroimaging 2019. In press.

65. Jager, K.J., et al., Confounding: What it is and how to deal with it. Kidney International, 2008. 73(3): p. 256-260.

66. Straus, S.E., et al., Evidence-Based Medicine E-Book : How to Practice and Teach EBM. 2018, Philadelphia, UNITED KINGDOM: Elsevier.

67. Moher, D., et al., CONSORT 2010 explanation and elaboration: updated guidelines for reporting parallel group randomised trials. BMJ, 2010. 340: p. c869.

68. Moher, D., et al., The CONSORT statement: revised recommendations for improving the quality of reports of parallel-group randomized trials. Ann Intern Med, 2001. 134(8): p. 657-62.

69. Fergusson, D., et al., Turning a blind eye: the success of blinding reported in a random sample of randomised, placebo controlled trials. BMJ, 2004. 328(7437): p. 432.

70. Hrobjartsson, A., et al., Blinded trials taken to the test: an analysis of randomized clinical trials that report tests for the success of blinding. Int J Epidemiol, 2007. 36(3): p. 654-63.

71. Sackett, D.L., Turning a blind eye: why we don't test for blindness at the end of our trials. BMJ (Clinical research ed.), 2004. 328(7448): p. 1136-1136.

72. Sackett, D.L., Commentary: Measuring the success of blinding in RCTs: don't, must, can't or needn't? Int J Epidemiol, 2007. 36(3): p. 664-5.

73. Senn, S.J., Turning a blind eye: authors have blinkered view of blinding. BMJ (Clinical research ed.), 2004. 328(7448): p. 1135-1136.

74. Bang, H., L. Ni, and C.E. Davis, Assessment of blinding in clinical trials. Control Clin Trials, 2004. 25(2): p. 143-56.

75. James, K.E., et al., An index for assessing blindness in a multi-centre clinical trial: disulfiram for alcohol cessation--a VA cooperative study. Stat Med, 1996. 15(13): p. 1421-34.

76. Rees, J.R., et al., Changes in beliefs identify unblinding in randomized controlled trials: a method to meet CONSORT guidelines. Contemporary Clinical Trials, 2005. 26(1): p. 25-37. 
77. Kolahi, J., H. Bang, and J. Park, Towards a proposal for assessment of blinding success in clinical trials: up-to-date review. Community Dent Oral Epidemiol, 2009. 37(6): p. 477-84.

78. Mathai, D.S., et al., The relationship between subjective effects induced by a single dose of ketamine and treatment response in patients with major depressive disorder: A systematic review. Journal of Affective Disorders, 2020. 264: p. 123-129.

79. Bahji, A., G.H. Vazquez, and C.A. Zarate, Comparative efficacy of racemic ketamine and esketamine for depression: A systematic review and meta-analysis. Journal of Affective Disorders, 2021. 278: p. 542-555.

80. Arabzadeh, S., et al. Does oral administration of ketamine accelerate response to treatment in major depressive disorder? Results of a double-blind controlled trial. Journal of affective disorders, 2018. 235, 236Ã çÂ?Â?241 DOI: 10.1016/j.jad.2018.02.056.

81. Berman, R., et al. Antidepressant effects of ketamine in depressed patients. Biological psychiatry, 2000. 47, 351Ã ĉÂÂ?354 DOI: 10.1016/s0006-3223(99)00230-9.

82. Burger, J., et al. A Double-Blinded, Randomized, Placebo-Controlled Sub-Dissociative Dose Ketamine Pilot Study in the Treatment of Acute Depression and Suicidality in a Military Emergency Department Setting. Military medicine, 2016. 181, 1195Ã ĉÂÂ]?1199 DOI: 10.7205/milmed-d-15-00431.

83. Canuso, C., et al., Esketamine nasal spray for rapid reduction of depressive symptoms in adult patients with major depressive disorder at imminent risk for suicide: Results from the phase 3 program. Neuropsychopharmacology, 2019. 44 (Supplement 1): p. 454-455.

84. Cao, Z., et al. Identifying Ketamine Responses in Treatment-Resistant Depression Using a Wearable Forehead EEG. IEEE transactions on biomedical engineering, 2018. (no pagination), DOI: 10.1109/tbme.2018.2877651.

85. Chen, M.H., et al., Persistent antidepressant effect of low-dose ketamine and activation in the supplementary motor area and anterior cingulate cortex in treatment-resistant depression: A randomized control study. Journal of Affective Disorders, 2018. 225: p. 709-714.

86. Daly, E.J., et al., Efficacy and Safety of Intranasal Esketamine Adjunctive to Oral Antidepressant Therapy in Treatment-Resistant Depression: A Randomized Clinical Trial. JAMA Psychiatry, 2018. 75(2): p. 139-148.

87. Diazgranados, N., et al., A Randomized Add-on Trial of an N-methyl-D-aspartate Antagonist in Treatment-Resistant Bipolar Depression. Archives of General Psychiatry, 2010. 67(8): p. 793-802.

88. Domany, Y., R. Shelton, and C. McCullumsmith Ketamine for acute suicidal ideation. An emergency department intervention: a randomized, double-blind, placebocontrolled, proof-of-concept trial. Depression and anxiety, 2019. DOI: 10.1002/da.22975.

89. Downey, D., et al. Comparing the actions of lanicemine and ketamine in depression: key role of the anterior cingulate. European neuropsychopharmacology, 2016. 26,

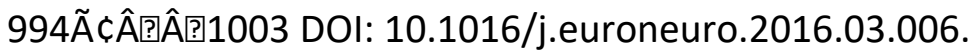

90. Fava, M., et al. Double-blind, placebo-controlled, dose-ranging trial of intravenous ketamine as adjunctive therapy in treatment-resistant depression (TRD). Molecular psychiatry, 2018. DOI: 10.1038/s41380-018-0256-5. 
91. Fedgchin, M., et al. Efficacy and Safety of Fixed-Dose Esketamine Nasal Spray Combined With a New Oral Antidepressant in Treatment-Resistant Depression: results of a Randomized, Double-Blind, Active-Controlled Study (TRANSFORM-1). The international journal of neuropsychopharmacology, 2019. DOI:

10.1093/ijnp/pyz039.

92. Grunebaum, M.F., et al., Ketamine for rapid reduction of suicidal thoughts in major depression: A midazolam-controlled randomized clinical trial. American Journal of Psychiatry, 2018. 175(4): p. 327-335.

93. Hu, Y., et al., Single i.v. ketamine augmentation of newly initiated escitalopram for major depression: Results from a randomized, placebo-controlled 4-week study. Psychological Medicine, 2016. 46(3): p. 623-635.

94. Ionescu, D.F., et al., Repeat-dose ketamine augmentation for treatment-resistant depression with chronic suicidal ideation: A randomized, double blind, placebo controlled trial. Journal of Affective Disorders, 2019. 243: p. 516-524.

95. Ionescu, D.F., et al., Esketamine Nasal Spray for Rapid Reduction of Depressive Symptoms in Patients with Major Depressive Disorder Who Have Active Suicide Ideation with Intent: Results of a Phase 3, Double-Blind, Randomized Study (ASPIRE II). International Journal of Neuropsychopharmacology, 2020.

96. Jafarinia, M., et al. Efficacy and safety of oral ketamine versus diclofenac to alleviate mild to moderate depression in chronic pain patients: a double-blind, randomized, controlled trial. Journal of affective disorders, 2016. 204, 1Ã ĉÂÂ?8 DOI: 10.1016/j.jad.2016.05.076.

97. Lai, R., et al. Pilot dose-response trial of i.v. ketamine in treatment-resistant depression. World journal of biological psychiatry, 2014. 15, 579Ã çÂ]Â?584 DOI: 10.3109/15622975.2014.922697.

98. Lapidus, K.A., et al., A randomized controlled trial of intranasal ketamine in major depressive disorder. Biol Psychiatry, 2014. 76(12): p. 970-6.

99. Li, C.T., et al., The effects of low-dose ketamine on the prefrontal cortex and amygdala in treatment-resistant depression: A randomized controlled study. Human Brain Mapping, 2016. 37(3): p. 1080-1090.

100. Loo, C., et al., Placebo-controlled pilot trial testing dose titration and intravenous, intramuscular and subcutaneous routes for ketamine in depression. Acta Psychiatrica Scandinavica, 2016. 134(1): p. 48-56.

101. Murrough, J.W., et al., Antidepressant efficacy of ketamine in treatment-resistant major depression: A two-site, randomized, parallel-arm, midazolam-controlled, clinical trial. Neuropsychopharmacology, 2012. 38: p. S151-S152.

102. Murrough, J., et al., Ketamine for rapid reduction of suicidal ideation: A randomized controlled trial. Psychological Medicine, 2015. 45(16): p. 3571-3580.

103. Nugent, A., et al. Ketamine has distinct electrophysiological and behavioral effects in depressed and healthy subjects. Molecular psychiatry, 2018. 1Ã çÂ]Â?]13 DOI: 10.1038/s41380-018-0028-2.

104. Phillips, J.L., et al., Single, Repeated, and Maintenance Ketamine Infusions for Treatment-Resistant Depression: A Randomized Controlled Trial. American Journal of Psychiatry, 2019. 176(5): p. 401-409.

105. Popova, V., et al., Efficacy and Safety of Flexibly Dosed Esketamine Nasal Spray Combined With a Newly Initiated Oral Antidepressant in Treatment-Resistant 
Depression: A Randomized Double-Blind Active-Controlled Study. American Journal of Psychiatry, 2019. 176(6): p. 428-438.

106. Singh, J.B., et al., A double-blind, randomized, placebo-controlled, dose-frequency study of intravenous ketamine in patients with treatment-resistant depression. American Journal of Psychiatry, 2016. 173(8): p. 816-826.

107. Sumner, R.L., et al., Ketamine Enhances Visual Sensory Evoked Potential Long-term Potentiation in Patients With Major Depressive Disorder. Biological Psychiatry: Cognitive Neuroscience and Neuroimaging, 2020. 5(1): p. 45-55.

108. Xu, Y., et al., Single bolus low-dose of ketamine does not prevent postpartum depression: a randomized, double-blind, placebo-controlled, prospective clinical trial. Archives of Gynecology and Obstetrics, 2017. 295(5): p. 1167-1174.

109. Zarate Jr, C.A., et al., A randomized trial of an N-methyl-D-aspartate antagonist in treatment-resistant major depression. Archives of General Psychiatry, 2006. 63(8): p. 856-864.

110. Gasser, P., et al., Safety and efficacy of lysergic acid diethylamide-assisted psychotherapy for anxiety associated with life-threatening diseases. J Nerv Ment Dis, 2014. 202(7): p. 513-20.

111. Grob, C.S., et al., Pilot Study of Psilocybin Treatment for Anxiety in Patients With Advanced-Stage Cancer. Archives of General Psychiatry, 2011. 68(1): p. 71-78.

112. Griffiths, R.R., et al., Psilocybin produces substantial and sustained decreases in depression and anxiety in patients with life-threatening cancer: A randomized double-blind trial. Journal of psychopharmacology, 2016. 30(12): p. 1181-1197.

113. Moreno, F.A., et al., Safety, tolerability, and efficacy of psilocybin in 9 patients with obsessive-compulsive disorder. Journal of Clinical Psychiatry, 2006. 67(11): p. 17351740.

114. Palhano-Fontes, F., et al., Rapid antidepressant effects of the psychedelic ayahuasca in treatment-resistant depression: a randomized placebo-controlled trial. Psychological Medicine, 2019. 49(4): p. 655-663.

115. Ross, S., et al., Rapid and sustained symptom reduction following psilocybin treatment for anxiety and depression in patients with life-threatening cancer: a randomized controlled trial. Journal of Psychopharmacology, 2016. 30(12): p. 11651180.

116. Bogenschutz, M.P., et al., Psilocybin-assisted treatment for alcohol dependence: $a$ proof-of-concept study. Journal of psychopharmacology, 2015. 29(3): p. 289-299.

117. Carhart-Harris, R.L., et al., Psilocybin with psychological support for treatmentresistant depression: an open-label feasibility study. The Lancet Psychiatry, 2016. 3(7): p. 619-627.

118. Davis, A.K., et al., Effects of Psilocybin-Assisted Therapy on Major Depressive Disorder: A Randomized Clinical Trial. JAMA Psychiatry, 2020.

119. Johnson, M.W., et al., Pilot study of the 5-HT2AR agonist psilocybin in the treatment of tobacco addiction. Journal of psychopharmacology, 2014. 28(11): p. 983-992.

120. Osório, F.d.L., et al., Antidepressant effects of a single dose of ayahuasca in patients with recurrent depression: a preliminary report. Brazilian Journal of Psychiatry, 2015. 37(1): p. 13-20.

121. Sanches, R.F., et al., Antidepressant effects of a single dose of ayahuasca in patients with recurrent depression: a SPECT study. Journal of clinical psychopharmacology, 2016. 36(1): p. 77-81. 
122. Thomas, G., et al., Ayahuasca-assisted therapy for addiction: results from a preliminary observational study in Canada. Curr Drug Abuse Rev, 2013. 6(1): p. 3042.

123. Nutt, D.J., L.A. King, and D.E. Nichols, Effects of Schedule I drug laws on neuroscience research and treatment innovation. Nat Rev Neurosci, 2013. 14(8): p. 577-85.

124. Ballou, S., et al., Open-label versus double-blind placebo treatment in irritable bowel syndrome: study protocol for a randomized controlled trial. Trials, 2017. 18(1): p. 234.

125. Chambers, C.D., B. Forstmann, and J.A. Pruszynski, Science in flux: Registered reports and beyond at the European Journal of Neuroscience. European Journal of Neuroscience, 2019. 49(1): p. 4-5.

126. Miller, G.A. and J.P. Chapman, Misunderstanding analysis of covariance. J Abnorm Psychol, 2001. 110(1): p. 40-8.

127. Wilkinson, S.T., et al., Impact of midazolam vs. saline on effect size estimates in controlled trials of ketamine as a rapid-acting antidepressant. Neuropsychopharmacology, 2019. 44(7): p. 1233-1238.

128. Doblin, R., Pahnke's "Good Friday experiment": A long-term follow-up and methodological critique. Journal of Transpersonal Psychology, 1991. 23(1): p. 1-28.

129. London, A.J., Equipoise in Research: Integrating Ethics and Science in Human Research. JAMA, 2017. 317(5): p. 525-526.

130. Walsh, B.T., et al., Placebo Response in Studies of Major DepressionVariable, Substantial, and Growing. JAMA, 2002. 287(14): p. 1840-1847.

131. Li, F., et al., Meta-Analysis of Placebo Response in Adult Antidepressant Trials. CNS Drugs, 2019. 33(10): p. 971-980.

132. Faries, D.E., et al., The Double-Blind Variable Placebo Lead-in Period: Results From Two Antidepressant Clinical Trials. Journal of Clinical Psychopharmacology, 2001. 21(6): p. 561-568.

133. Kaptchuk, T.J., et al., Do "placebo responders" exist? Contemporary Clinical Trials, 2008. 29(4): p. 587-595.

134. Fava, M., et al., The problem of the placebo response in clinical trials for psychiatric disorders: culprits, possible remedies, and a novel study design approach. Psychother Psychosom, 2003. 72(3): p. 115-27.

135. Jones, B. and M. Kenward, Design and Analysis of Cross-Over Trials. 2015: New York: Chapman and Hall/CRC.

136. Carhart-Harris, R.L., et al., Psilocybin with psychological support for treatmentresistant depression: an open-label feasibility study. Lancet Psychiatry, 2016. 3(7): p. 619-27.

137. Williams, N.R., et al., Attenuation of Antidepressant Effects of Ketamine by Opioid Receptor Antagonism. American Journal of Psychiatry, 2018. 175(12): p. 1205-1215.

138. Anand, A., et al., Attenuation of the Neuropsychiatric Effects of Ketamine With Lamotrigine: Support for Hyperglutamatergic Effects of N-methyl-D-aspartate Receptor Antagonists. Archives of General Psychiatry, 2000. 57(3): p. 270-276.

139. Deakin, J.F.W., et al., Glutamate and the Neural Basis of the Subjective Effects of Ketamine: A Pharmaco-Magnetic Resonance Imaging Study. Archives of General Psychiatry, 2008. 65(2): p. 154-164.

140. Kraehenmann, R., et al., LSD Increases Primary Process Thinking via Serotonin $2 A$ Receptor Activation. Front Pharmacol, 2017. 8: p. 814. 
141. Vollenweider, F.X., et al., Psilocybin induces schizophrenia-like psychosis in humans via a serotonin-2 agonist action. NeuroReport, 1998. 9(17): p. 3897-3902.

142. Holze, F., et al., Acute dose-dependent effects of lysergic acid diethylamide in a double-blind placebo-controlled study in healthy subjects. Neuropsychopharmacology, 2020.

143. Carroll, R.J. and L.A. Stefanski, Approximate Quasi-likelihood Estimation in Models With Surrogate Predictors. Journal of the American Statistical Association, 1990. 85(411): p. 652-663.

144. Cartwright, N. and J. Hardie, Evidence-Based Policy: A Practical Guide to Doing It Better 2015, New York: Oxford Scholarship Online. 